\title{
Nanomaterial-mediated autophagy: coexisting hazard and health benefits in biomedicine
}

\author{
Xiaoli Feng ${ }^{1 \dagger}$, Yaqing Zhang ${ }^{2 \dagger}$, Chao Zhang ${ }^{3}$, Xuan Lai ${ }^{2}$, Yanli Zhang ${ }^{1}$, Junrong $\mathrm{Wu}^{2}$, Chen $\mathrm{Hu}^{2}$ and \\ Longquan $\mathrm{ShaO}^{2^{*}}$ (D)
}

\begin{abstract}
Background: Widespread biomedical applications of nanomaterials (NMs) bring about increased human exposure risk due to their unique physicochemical properties. Autophagy, which is of great importance for regulating the physiological or pathological activities of the body, has been reported to play a key role in NM-driven biological effects both in vivo and in vitro. The coexisting hazard and health benefits of NM-mediated autophagy in biomedicine are nonnegligible and require our particular concerns.

Main body: We collected research on the toxic effects related to NM-mediated autophagy both in vivo and in vitro. Generally, NMs can be delivered into animal models through different administration routes, or internalized by cells through different uptake pathways, exerting varying degrees of damage in tissues, organs, cells, and organelles, eventually being deposited in or excreted from the body. In addition, other biological effects of NMs, such as oxidative stress, inflammation, necroptosis, pyroptosis, and ferroptosis, have been associated with autophagy and cooperate to regulate body activities. We therefore highlight that NM-mediated autophagy serves as a double-edged sword, which could be utilized in the treatment of certain diseases related to autophagy dysfunction, such as cancer, neurodegenerative disease, and cardiovascular disease. Challenges and suggestions for further investigations of NM-mediated autophagy are proposed with the purpose to improve their biosafety evaluation and facilitate their wide application. Databases such as PubMed and Web of Science were utilized to search for relevant literature, which included all published, Epub ahead of print, in-process, and non-indexed citations.
\end{abstract}

Conclusion: In this review, we focus on the dual effect of NM-mediated autophagy in the biomedical field. It has become a trend to use the benefits of NM-mediated autophagy to treat clinical diseases such as cancer and neurodegenerative diseases. Understanding the regulatory mechanism of NM-mediated autophagy in biomedicine is also helpful for reducing the toxic effects of NMs as much as possible.

Keywords: Nanomaterials, Autophagy, Physicochemical property, Hazard, Medical benefit, Pyroptosis, Non-coding RNAs, Anticancer, Neurodegenerative disease

\footnotetext{
* Correspondence: shaolongquan@smu.edu.cn

${ }^{\dagger}$ Feng Xiaoli and Zhang Yaqing contributed equally to this work.

${ }^{2}$ Nanfang Hospital, Southern Medical University, 1838 North Guangzhou

Street, Guangzhou 510515, China

Full list of author information is available at the end of the article
}

(c) The Author(s). 2020 Open Access This article is licensed under a Creative Commons Attribution 4.0 International License, which permits use, sharing, adaptation, distribution and reproduction in any medium or format, as long as you give appropriate credit to the original author(s) and the source, provide a link to the Creative Commons licence, and indicate if changes were made. The images or other third party material in this article are included in the article's Creative Commons licence, unless indicated otherwise in a credit line to the material. If material is not included in the article's Creative Commons licence and your intended use is not permitted by statutory regulation or exceeds the permitted use, you will need to obtain permission directly from the copyright holder. To view a copy of this licence, visit http://creativecommons.org/licenses/by/4.0/ The Creative Commons Public Domain Dedication waiver (http://creativecommons.org/publicdomain/zero/1.0/) applies to the data made available in this article, unless otherwise stated in a credit line to the data. 


\section{Background}

Nanomaterials (NMs) are defined as materials containing particles with one or more external dimensions in the size range from 1 to $100 \mathrm{~nm}$, among which particulate NMs are also known as nanoparticles (NPs) [1]. Based on their unique physical and chemical properties, a growing number of studies have paid attention to their application prospects in the biomedical field to develop novel diagnostic or therapeutic tools, such as for drug delivery [2], biosensors [3], bioprobes [4], and tissue engineering materials [5]. Concurrent with wide nano applications are increasing exposure risks of NMs to the human body. In addition to environmental exposure, NMs and their composite systems can directly contact tissue or a damaged wound, as they are inhaled, taken orally, or even injected directly into the biological system in a medical situation [6-9]. For these considerations, a large number of studies have investigated the biological hazard of NMs through varying exposure pathways [1013]. In view that NMs are more chemically active than their bulk counterparts, NMs distributed in different organs can cause distinct toxic effects through interacting with cells, proteins, or DNA after entering the body [14-17]. At present, the most widely investigated mechanisms of NM-driven toxicity include oxidative stress, inflammatory response and cell apoptosis, but other underlying mechanisms remain obscure and require our particular attention [18-20].

The definition of autophagy has been identified as an emerging mechanism of NM-induced toxicity in recent research. Autophagy (also called autophagic flux) is a conserved catabolic process by which impaired organelles and proteins are sequestered in double-membraned vesicles called autophagosomes [21]. In the initial step, the intracellular microtubule-associated protein light chain 3 (LC3) precursor is hydrolyzed by the autophagyrelated protein 4 (Atg4) to generate water-soluble LC3-I, which is distributed in the cytoplasm. Subsequently, LC3-I covalently binds phosphatidyl ethanolamine (PE) under the synergistic action of Atg7 and the Atg12Atg5-Atg16l complex to generate lipid-soluble LC3-II, which participates in autophagosome membrane extension [22]. Finally, the fusion of autophagosomes with lysosomes to form autolysosomes leads to the degradation of the encapsulated materials to their components, which can contribute to cell growth and maintain cell homeostasis. Autophagy can be activated as a protective mechanism under both physiological and pathological conditions to maintain or restore cell homeostasis [23]. Conversely, once out of balance following NM exposure, autophagy can also cause cell damage such as mitochondrial and lysosomal dysfunction, endoplasmic reticulum impairment, and even programmed cell death [24-27].
The biological behavior of NMs is regulated by multiple factors, among which autophagy not only initiates the upstream responses but also may be result from other biological effects [28]. For example, zinc oxide ( $\mathrm{ZnO})$ NPs and silica NPs (SiNPs) have been reported to disrupt the activity of antioxidant enzymes (catalase, glutathione peroxidase), resulting in intracellular oxidative stress imbalance and increased ROS levels, as well as activated excessive autophagy by inhibiting the PI3K/ Akt/mTOR signaling pathway, leading to autophagic cell death $[20,29]$. Moreover, normal autophagy, as an effective means for cells to resist foreign stimulation (such as NM exposure), can alleviate the apoptosis of Leydig TM3 cells [30]. However, when autophagic flux is blocked, such as autophagy-lysosome degradation functional declines following graphene oxide (GO) exposure, p62 protein as the substrate of autophagy accumulates substantially in the cell and even triggers apoptosis [31]. It is worth noting that increasing evidence indicates that new types of pathological changes, including pyroptosis, necroptosis, and ferroptosis, are also closely related to autophagy [32-34]. Combined with the above observations, autophagy may play different roles in the biological behavior of NMs, such as the promoter, transfer station, or effect endpoint, and this regulation mode may play completely opposite roles in physiological and pathological states. Studies in recent years have shown that autophagy can lead to the development of cancer [35], neurodegenerative disease [36], autoimmune disease [37], and cardiovascular disease [38]. Therefore, how to use NMs including their composites to regulate the autophagy process has very important reference value for the effective clinical treatment of these diseases.

This review first introduces the application of NMs in biomedical science based on different physicochemical properties and classifications. In view of the increasing exposure risk of NMs and their composites during the diagnosis and therapy process, we next describe their in vivo and in vitro toxic effects, which mainly focus on the regulation of NM-mediated autophagy. Moreover, the important role of autophagy in pathological conditions has been identified; thus, more attention should be paid to how to use NM-mediated autophagy as an effective therapeutic tool to promote the treatment of clinical diseases. We hope this review can help to understand the underlying mechanisms by which NMs regulate autophagy both in physiological and pathological states and further make better use of these advantages in the biomedical field.

\section{Search strategy}

The search strategy of this paper is shown in Fig. 1. Databases such as PubMed and Web of Science were utilized to search the literature for relevant articles, which 


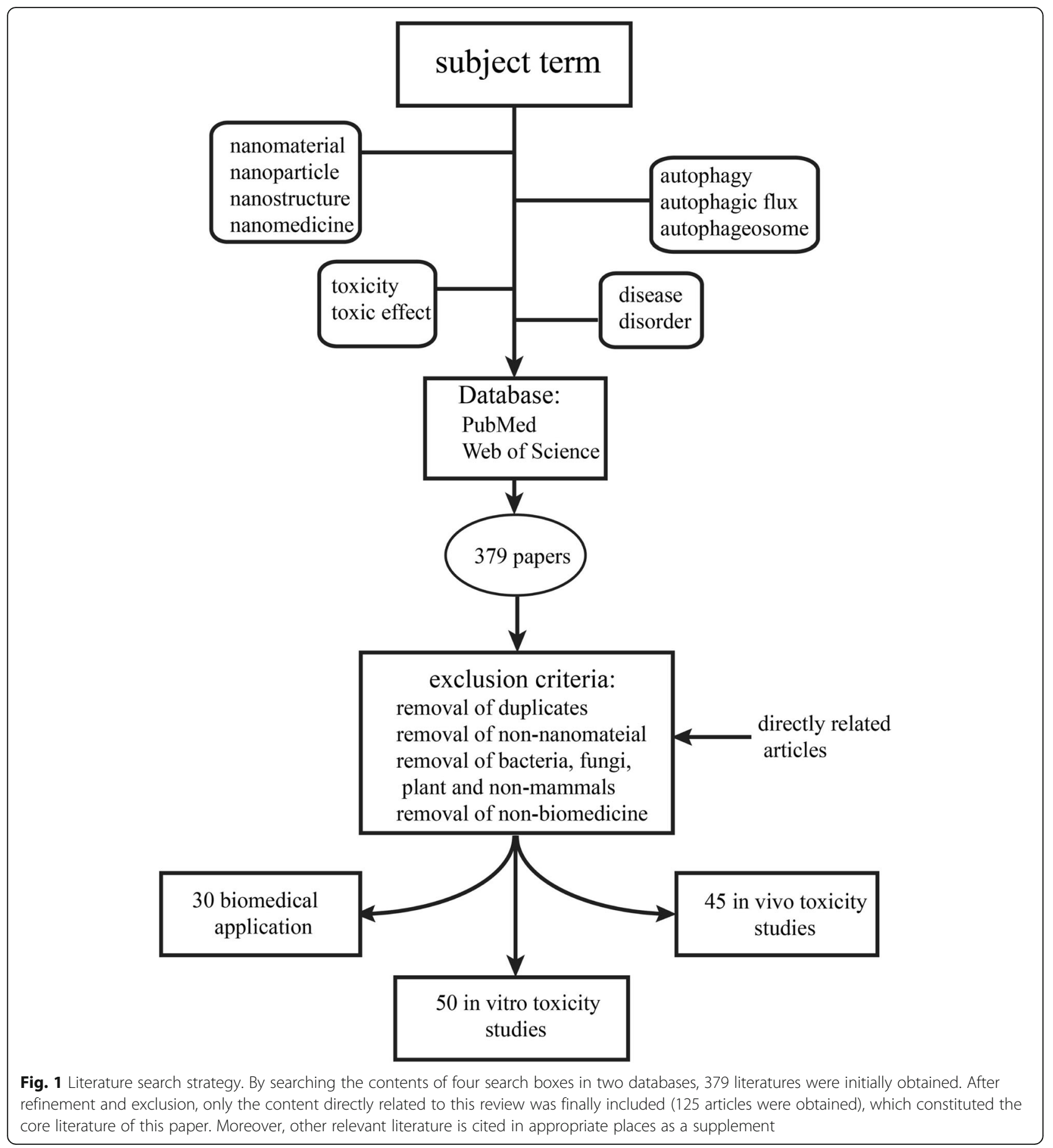

included all published, Epub ahead of print, in-process, and non-indexed citations. The purpose of this search was to look for papers related to autophagy mediated by NMs, not only in terms of its toxic effects but also biomedical treatments, such as those for cancer and neurological diseases. The retrieved articles were published from January 2009 to March 2020, and articles published in the past 5 years were preferentially chosen. Article types included research articles and reviews. The subject terms used in this search were as follows: (1) "nanomaterial" or "nanoparticle" or "nanostructure" or "nanomedicine" and (2) "autophagy" or "autophagic flux" or "autophagosome" and (3) "toxicity" or "toxic effect" and "diseases" or "disorder" (4) and (5) "biomedical application". A total of 379 results were generated, and 125 directly related studies were obtained after elimination. 
Exclusion criteria included the following:

- Editorials and commentaries;

- Research unrelated to NMs;

- Non-biomedical applications such as optoelectronic and mechanical applications;

- Studies involving bacteria, fungi, plants, and nonmammals such as shellfish and zebrafish;

- Duplicate references.

\section{Characteristics and applications of NMs in biomedicine}

Nanomaterials have characteristics of a small size effect, high specific surface area, and quantum size effect, among others, which are obviously different from those of their bulk counterparts [39]. These effects largely determine their melting point, optical properties, chemical reactivity, magnetism, and superconductivity, contributing to their extensive application prospects in the field of biomedicine. A large number of studies have reported nano applications for the innovation of traditional diagnostic and treatment technologies, among which the most widely used NMs are listed in this review.

\section{Mesoporous silica NMs (MSNs)}

Mesoporous silica mostly refers to amorphous silicon oxide materials with pores ranging from 2 to $50 \mathrm{~nm}$. Mesoporous silicon-based NMs are composed of amorphous skeletons with a high pore capacity, are uniform with an adjustable pore size, and have an available functionalization and interface effect [40]. Furthermore, this kind of material has good biocompatibility, contributing to its wide application prospects in fields of biotechnology such as drug delivery [41] and gene therapy $[42,43]$. The discovery of MSNs has greatly promoted the development of sustained and controlled drug release field. Conversely, we should note that MSNs can be degraded to a certain extent in vivo, but their degradation rate and degree are unpredictable and uncontrollable $[44,45]$. How to adjust the degradation rate of MSNs to meet the clinical requirement, or reduce the potential risks introduced by its long-term survival in the human body by increasing their degradation level, is still the challenge of current research.

\section{Magnetic NMs}

Functional NMs with a magnetic field response possess good modifiability, special in vivo metabolic behaviors, and unique magnetic properties, showing great application value in biological detection, disease diagnosis, and treatment. In recent years, a variety of functional composites based on iron oxide $\left(\mathrm{Fe}_{2} \mathrm{O}_{3}\right)$ or ferrosoferric oxide $\left(\mathrm{Fe}_{3} \mathrm{O}_{4}\right)$ NPs have been widely used in tumor molecular imaging and magnetic hyperthermia [46-48]. It is worth noting that many challenges persist in the clinical transformation of magnetic functional NMs. For example, the thermal conversion efficiency of magnetic NPs doped in magnetic hydrogel under magnetic field is low [49]. The high efficiency of the magneto-thermal medium will further weaken its biosecurity [50]. How to achieve low toxicity and high efficiency simultaneously is still the focus of future research.

\section{Metal NMs}

Various morphologies of gold $(\mathrm{Au}) \mathrm{NMs}$ have been reported in the literature, such as Au nanotubes [51], $\mathrm{Au}$ nanocages [52], hollow $\mathrm{Au}$ nanospheres [53] and $\mathrm{Au}$ nanorods [54]. Among them, Au nanorods are typical representatives. They have a plasma absorption peak with strong absorption in the near-infrared region [55], contributing to a good photothermal conversion efficiency [56]. Thus, they are often used in drug delivery and cancer treatment [57]. It should be noted that the shape of the NMs affects their intracellular uptake to a large degree. It has been reported that spherical AuNPs are more likely to enter cells than $\mathrm{Au}$ nanorods and cause downstream toxic effects [58]. In the preparation of multifunctional nano composites based on AuNPs, chemical reagents are often added as stabilizers (e.g., cetyl trimethylammonium bromide (CTAB)). However, CTAB not only hinders the coupling of Au nanorods with biomolecules [59], but also has certain biological toxicity. Silver (Ag) NPs are one of the most commonly used antibacterial materials. The antibacterial effects of AgNPs partly depend on their solubility. In the solution, AgNPs will release a high concentration of $\mathrm{Ag}$ ions, which can anchor the protein groups on the cell wall of bacteria and cause protein denaturation to form pores, eventually leading to increased permeability of the cell membrane and an imbalance of homeostasis [60]. In addition, studies have reported that AgNPs entering cells may directly damage DNA, RNA, and chromatin [61, 62]. These findings further lead to the consideration of the biocompatibility of AgNPs in clinical applications.

\section{Metal oxide NMs}

$\mathrm{ZnO}$ NPs is often used in daily life as an additive in sunscreen products so that it can be in direct contact with human skin. In the field of biomedicine, it is widely used in biological imaging and antibacterial and anti-tumor applications [63-65]. Especially in the antibacterial field, it has a strong and broad-spectrum antibacterial effect on both gram-positive and gram-negative bacteria [66]. $\mathrm{ZnO}$ NPs are now considered to destroy lipids and proteins on the cell wall of bacteria, causing increased cell wall permeability and release of contents, finally leading to bacterial death. In addition, $\mathrm{ZnO}$ NPs can release free zinc ions in solution, which then produce reactive oxygen species (ROS) to kill bacterial cell bodies [67, 68]. 
Titanium dioxide $\left(\mathrm{TiO}_{2}\right)$ is a kind of semiconductor material existing in nature, which has characteristics of stable chemical performance, easy availability at a cheap price, and high catalytic activity [69]. Nano-sized $\mathrm{TiO}_{2}$ has the physicochemical properties of a large specific surface area and small size simultaneously, which has attracted extensive attention in terms of photothermal treatment of tumors, surface modification of implants, and antibacterial agents [70-72]. At present, studies on the biological behaviors of $\mathrm{ZnO}$ and $\mathrm{TiO}_{2} \mathrm{NMs}$ are relatively mature and comprehensive.

\section{Carbon-based NMs}

Carbon-based NMs have shown great potential in drug delivery due to their unique characteristics of high specific surface area, good thermal conductivity, and easy surface modification. The hollow structures of fullerenes and carbon nanotubes (CNTs) could be used to carry drugs or other small molecules [73]. Large numbers of $\pi$ electrons on the surface of graphene and CNTs can be used to load hydrophobic drugs [74, 75]. In addition, graphene and CNTs are also used as photothermal reagents for tumor photothermal therapy due to their strong near-infrared absorption capacity [76, 77]. Compared with other carbon-based NMs, the biocompatibility of the graphene family is relatively lacking. Although most in vivo studies have suggested that graphene-based NMs have good biological safety, there is still evidence indicating that they may cause oxidative stress by transferring electrons, leading to a series of toxic effects [78]. Conversely, tactics to improve the encapsulation efficiency of two-dimensional NMs including graphene and reduce the uncontrollable release of loaded drugs remains a challenge for future research.

Due to their wide applications in biomedical field, NMs and their composite systems can come in contact with normal tissue or a damaged wound, as they are inhaled, taken orally, or even injected directly into the biological system in medical situations. Considering that NMs are more chemically active than their bulk counterparts and can interact with biomolecules of similar small size such as proteins or DNA in vivo [15-17], it is important to rigorously investigate their biological behaviors.

\section{Distribution and metabolism of NMs in vivo}

To simulate nano exposure under environmental or medical working conditions, different administration routes in animal models were used (summarized in Table 1), including airway exposure [79, 80], oral gavage [81], intravenous administration [82], intraperitoneal administration [83], and subcutaneous administration [84]. It should be noted that the administration route largely determines the distribution pattern and further target organ toxicity of NMs in the body. For example, intravenous and intraperitoneal injection of $\mathrm{ZnO}$ NPs leads to their deposition in the liver, spleen, and kidneys along with the blood circulation $[85,86]$, while nano$\mathrm{ZnO}$ administered through intratracheal instillation mainly cause significant pulmonary inflammation in mice [87]. The physical and chemical properties are another important factor affecting the biological distribution of NMs. Larger GO aggregates are deposited near the injection site in Balb/c mice after intraperitoneal injection, while smaller aggregates are detected more easily absorbed and deposited in the proximity of the spleen serosa and liver [88]. In addition, a significant accumulation of polyethylene glycol (PEG) functionalized GO rather than pristine GO has been observed in the reticuloendothelial system (RES) after intraperitoneal injection, without obvious short-term toxicity [88], indicating a role of surface modification.

The excretion of NMs is the final step of their metabolic kinetics in vivo, which is closely related with their distribution. For instance, intravenously and subcutaneously injected SiNPs accumulate in the liver and are primarily eliminated through hepatic processing and excreted via the biliary or feces route $[89,90]$. Interestingly, Qi et al. [91] found that a majority of GO nanoplatelets (GONPs) and oxidized multiwalled carbon nanotubes (oMWCNTs) were excreted through feces after respective intravenous administration, while coexposure to both NMs led to urine excretion. This alteration was potentially due to chemical combination between NMs, an increased aggregation size, or the mutual influence of both mechanisms. Although the renal and fecal routes have been considered the main elimination routes for most NMs, the literature is insufficient to draw conclusions about their detailed clearance mechanism in vivo.

\section{Organ injury related to NM-driven autophagy Hepatotoxicity}

The liver is rich in lysosomes, and thus, under high levels of hunger stress, large amounts of autolysosomes can be produced and provide amino acids and glucose required for energy production of liver cells by degrading substrates to maintain normal physiological activities of the liver [92, 93]. Once autophagy is disrupted, the liver may show pathological changes such as viral hepatitis, or even the development of liver cancer [94-96]. NMs including AgNPs [97], rare earth upconversion NPs (UCNs) [98], and polyamidoamine dendrimers (PAMAM) NPs [99] have been reported to induce excessive autophagy to cause liver damage, characterized by hematoxylin and eosin (HE) staining in liver inflammatory cell infiltration, or dotted necrosis, and increased serum alanine aminotransferase (ALT) and aspartate aminotransferase (AST) activity. Moreover, the autophagy induced by SiNPs may further promote liver cell 
Table 1 In vivo toxicological studies of NPs mediated autophagy

\begin{tabular}{|c|c|c|c|c|c|c|c|c|c|}
\hline$\overline{N P s}$ & Size $(n m)$ & Coating & Animal model & Administration & $\begin{array}{l}\text { Dose } \\
(\mathrm{mg} / \mathrm{kg} \mathrm{BW})\end{array}$ & $\begin{array}{l}\text { Exposure } \\
\text { time }\end{array}$ & Organ toxicity & $\begin{array}{l}\text { Autophagy } \\
\text { alterations }\end{array}$ & References \\
\hline $\mathrm{TiO}_{2} \mathrm{NPs}$ & $19.3 \pm 5.4$ & bare & $\begin{array}{l}\text { A/J Jms Slc } \\
\text { mice (5 weeks } \\
\text { old) }\end{array}$ & inhalation & $\begin{array}{l}2.5,5.0,10.0 \\
\left(\mathrm{mg} / \mathrm{m}^{3}\right)\end{array}$ & $\begin{array}{l}6 \text { h per } \\
\text { day for } 4 \\
\text { weeks }\end{array}$ & $\begin{array}{l}\text { 1. hyperplasia } \\
\text { and hemorrhage } \\
\text { 2. inflammatory } \\
\text { response in the } \\
\text { lung }\end{array}$ & $\begin{array}{l}\text { induction of } \\
\text { autophagy } \\
\text { LC3 } \uparrow \text { Beclin } 1 \uparrow\end{array}$ & [79] \\
\hline Cd-based QDs & 12 & bare & $\begin{array}{l}\text { male Balb/c } \\
\text { mice }\end{array}$ & tail vein & $\begin{array}{l}0.1 \sim 0.3 \\
\mathrm{nmol}\end{array}$ & $24 \mathrm{~h}$ & $\begin{array}{l}\text { 1. increase of } \\
\text { aspartate } \\
\text { transaminase } \\
\text { and glutamate } \\
\text { pyruvate } \\
\text { transaminase } \\
\text { 2. haemocytes } \\
\text { and necrosis in } \\
\text { the live and } \\
\text { kidney }\end{array}$ & $\begin{array}{l}\text { stimulated } \\
\text { autophagic flux } \\
\text { LC3 } 962 \downarrow\end{array}$ & [80] \\
\hline \multirow[t]{2}{*}{ ZnO NPs } & 47.8 & bare & $\begin{array}{l}\text { Female Balb/c } \\
\text { mice ( } 8 \text { weeks } \\
\text { old) }\end{array}$ & $\begin{array}{l}\text { Intraperitoneal } \\
\text { or intravenous } \\
\text { injection }\end{array}$ & 10 & $\begin{array}{l}\text { once per } \\
\text { week for } \\
4 \text { weeks }\end{array}$ & $\begin{array}{l}\text { increase in } \\
\text { serum creatinine } \\
\text { and BUN in the } \\
\text { kidney }\end{array}$ & $\begin{array}{l}\text { autophagy } \\
\text { induction } \\
\text { autophagosome } \\
\text { accumulation, } \\
\text { LC3 } \uparrow\end{array}$ & [81] \\
\hline & $200-250$ & bare & $\begin{array}{l}\text { Balb/c mice } \\
\text { (6-8 weeks old) }\end{array}$ & oral gavage & 200,500 & 6 days & $\begin{array}{l}\text { massive } \\
\text { infiltration of } \\
\text { inflammatory } \\
\text { cells and DNA } \\
\text { damage in the } \\
\text { liver }\end{array}$ & $\begin{array}{l}\text { autophagy } \\
\text { induction } \\
\text { autophagosome } \\
\text { accumulation }\end{array}$ & [82] \\
\hline UCNs & $<200$ & bare & $\begin{array}{l}\text { male } \text { C57BL/6 J } \\
\text { mice }(6-8 \\
\text { weeks old) }\end{array}$ & tail vein & 100 & $24 \mathrm{~h}$ & $\begin{array}{l}\text { 1. inflammatory } \\
\text { cell infiltrates } \\
\text { 2. ALT levels } \\
\text { increased in the } \\
\text { liver }\end{array}$ & $\begin{array}{l}\text { induction of } \\
\text { autophagy } \\
\text { autophagosomes } \\
\text { accumulation } \\
\text { LC3 } \uparrow \text { LAMP } \uparrow\end{array}$ & [83] \\
\hline PAMAM NPS & $5 \sim 6$ & bare & $\begin{array}{l}\text { female Balb/c } \\
\text { mice }(6-8 \\
\text { weeks old) }\end{array}$ & $\begin{array}{l}\text { intraperitoneal } \\
\text { injection }\end{array}$ & 100 & 10 days & $\begin{array}{l}\text { 1. hepatocytic } \\
\text { necrosis and } \\
\text { vacuolization } \\
\text { 2. weight } \\
\text { decreased } \\
\text { 3. ALT and AST } \\
\text { increased in the } \\
\text { liver }\end{array}$ & $\begin{array}{l}\text { induction of } \\
\text { autophagy } \\
\text { accumulation of } \\
\text { vacuolization } \\
\text { LC3 } \uparrow\end{array}$ & [84] \\
\hline $\begin{array}{l}\text { Graphene } \\
\text { nanoplatelets }\end{array}$ & $3 \sim 4$ & bare & $\begin{array}{l}\text { ICR mice } 6 \\
\text { Weeks old) }\end{array}$ & $\begin{array}{l}\text { intratracheal } \\
\text { instillation }\end{array}$ & $2.5,5$ & $\begin{array}{l}1,7,14, \\
\text { and } 28 \\
\text { days }\end{array}$ & $\begin{array}{l}\text { 1. hyperplasia } \\
\text { and hemorrhage } \\
\text { 2. inflammatory } \\
\text { response in the } \\
\text { lung }\end{array}$ & $\begin{array}{l}\text { blockade of } \\
\text { autophaic flux } \\
\text { LC3 } \uparrow \text { P62 } \uparrow\end{array}$ & [85] \\
\hline PAMAM NPS & - & bare & $\begin{array}{l}\text { male Balb/c } \\
\text { mice (6-10 } \\
\text { weeks old) }\end{array}$ & $\begin{array}{l}\text { intratracheal } \\
\text { administration }\end{array}$ & 50 & $24 \mathrm{~h}$ & $\begin{array}{l}\text { lung } \\
\text { inflammation } \\
\text { and changed } \\
\text { the } \\
\text { lung elastance }\end{array}$ & $\begin{array}{l}\text { induction of } \\
\text { autophagy } \\
\text { LC3 } \uparrow\end{array}$ & [86] \\
\hline SWCNTS & - & $\begin{array}{l}\text { COOH-CNT } \\
\text { PABS-CNT } \\
\text { PEG-CNT }\end{array}$ & $\begin{array}{l}\text { male Balb/c } \\
\text { mice( } 6-8 \text { weeks } \\
\text { old) }\end{array}$ & $\begin{array}{l}\text { intratracheal } \\
\text { administration }\end{array}$ & 15 & $24 \mathrm{~h}$ & $\begin{array}{l}\text { 1. Acute } \\
\text { pulmonary } \\
\text { inflammation } \\
\text { 2. severe lung } \\
\text { edema }\end{array}$ & $\begin{array}{l}\text { induction of } \\
\text { autophagy } \\
\text { autophagosomes } \\
\text { accumulation } \\
\text { LC3 } \uparrow\end{array}$ & [87] \\
\hline CdTe QDs & 4.08 & bare & $\begin{array}{l}\text { male Balb/c } \\
\text { mice ( } 8-10 \\
\text { weeks old) }\end{array}$ & $\begin{array}{l}\text { intravenous } \\
\text { injection }\end{array}$ & $\begin{array}{l}8 \text { and } 16 \\
\mathrm{nmol} / \mathrm{kg}\end{array}$ & $24 \mathrm{~h}$ & $\begin{array}{l}\text { 1. increase in } \\
\text { uric acid, } \\
\text { creatinine and } \\
\text { BUN } \\
\text { 2. UPR and ER- } \\
\text { phagy in the } \\
\text { kidney } \\
\text { and liver }\end{array}$ & $\begin{array}{l}\text { induction of } \\
\text { autophagy } \\
\text { LC3 }\end{array}$ & [88] \\
\hline
\end{tabular}


Table 1 In vivo toxicological studies of NPs mediated autophagy (Continued)

\begin{tabular}{|c|c|c|c|c|c|c|c|c|c|}
\hline NPs & Size $(n m)$ & Coating & Animal model & Administration & $\begin{array}{l}\text { Dose } \\
(\mathrm{mg} / \mathrm{kg} \mathrm{BW})\end{array}$ & $\begin{array}{l}\text { Exposure } \\
\text { time }\end{array}$ & Organ toxicity & $\begin{array}{l}\text { Autophagy } \\
\text { alterations }\end{array}$ & References \\
\hline $\mathrm{Fe}_{3} \mathrm{O}_{4} \mathrm{NPS}$ & $15 \sim 20$ & PLGA & $\mathrm{NIH}$ mice & $\begin{array}{l}\text { intraperitoneal } \\
\text { injection }\end{array}$ & 10 & $\begin{array}{l}2,4,8,10 \\
\text { and } 12 \\
\text { days }\end{array}$ & $\begin{array}{l}\text { extensive } \\
\text { accumulation of } \\
\text { autophagosome } \\
\text { in the kidney } \\
\text { and spleen }\end{array}$ & $\begin{array}{l}\text { induction of } \\
\text { autophagy } \\
\text { autophagosomes } \\
\text { accumulation } \\
\text { LC3 } \uparrow\end{array}$ & [89] \\
\hline MWCNTs & $10 \sim 12$ & bare & $\begin{array}{l}\text { male Wistar } \\
\text { rats }(200-220 \mathrm{~g})\end{array}$ & $\begin{array}{l}\text { intraperitoneal } \\
\text { injection }\end{array}$ & 2.5 & $\begin{array}{l}\text { once per } \\
\text { day for } \\
14 \text { days }\end{array}$ & $\begin{array}{l}\text { decrease in } \\
\text { hippocampal } \\
\text { synaptic } \\
\text { plasticity and } \\
\text { spatial cognition } \\
\text { in the brain }\end{array}$ & $\begin{array}{l}\text { induction of } \\
\text { autophagy } \\
\text { LC3 } \uparrow \text { Becline } \uparrow\end{array}$ & [90] \\
\hline CoCr NPs & $80 \pm 14.6$ & bare & $\begin{array}{l}\text { C57BL/6 mice } \\
\text { (12 weeks old) }\end{array}$ & $\begin{array}{l}\text { intravenous } \\
\text { injection }\end{array}$ & $\begin{array}{l}0.12 \mathrm{mg} \text { per } \\
\text { mouse }\end{array}$ & $\begin{array}{l}9.5,12.5 \\
\text { days of } \\
\text { pregnancy }\end{array}$ & $\begin{array}{l}\text { 1. increase in } \\
\text { GFAP in } \\
\text { hippocampus; } \\
\text { 2. release IL-6 } \\
\text { and DNA injury } \\
\text { in the brain }\end{array}$ & $\begin{array}{l}\text { blockade of } \\
\text { autophaic flux } \\
\text { LC3 } \uparrow \text { P62 } \uparrow\end{array}$ & [91] \\
\hline SiNPs & 62 & bare & $\begin{array}{l}\text { Male and } \\
\text { female ICR } \\
\text { mice (8 weeks } \\
\text { old) }\end{array}$ & $\begin{array}{l}\text { intravenous } \\
\text { injection }\end{array}$ & $\begin{array}{l}29.5,103.5 \\
\text { and } 177.5\end{array}$ & 14 ays & $\begin{array}{l}\text { 1.inhibitory } \\
\text { effect on the } \\
\text { expression of } \\
\text { ICAM-1 and } \\
\text { VCAM-1 } \\
\text { 2. impair } \\
\text { angiogenesis }\end{array}$ & $\begin{array}{l}\text { induction of } \\
\text { autophagy } \\
\text { LC3 } \uparrow\end{array}$ & [92] \\
\hline
\end{tabular}

apoptosis through the accumulation of p62 protein and down-regulation of mammalian target of rapamycin (mTOR) [100].

\section{Pulmonary toxicity}

Environmental exposure to NMs significantly increases the possibility of entry into the human body through the respiratory tract and deposition mostly in the lungs. At present, a large amount of evidence indicates that NMmediated autophagy is closely related to pulmonary toxicity [80, 101, 102]. For example, Park et al. [103] reported that the subchronic inflammatory response in the lungs caused by graphene nanoplatelets was associated with excessive autophagy, which suppressed ATP production and led to mitochondrial damage. Similar pulmonary injury was also detected in PAMAM NP and single-walled carbon nanotube (SWCNTs)-treated mice through Akt-TSC2-mTOR signaling [104, 105]. Interestingly, after carboxylation modification, the autophagy activity of multi-wall carbon nanotubes was significantly reduced, as manifested by the decreasing expression of LC3 [106, 107]. Moreover, the degree of carboxylation was negatively correlated with the pulmonary inflammatory response within a certain range, suggesting that the surface modification of NMs could help improve their biosafety. In addition to the effect of direct exposure, after maternal exposure to carbon black NPs during pregnancy, these NPs could cross the placental barrier and deposit in the lungs of offspring mice, leading to pulmonary fibrosis by inhibiting autophagy activation
[108]. In our opinion, this finding highlights the importance and need for strict monitoring of women exposed to NMs and their composites during pregnancy.

\section{Nephrotoxicity}

Nanomaterials, especially those with a smaller particle size $(<20 \mathrm{~nm})$, are excreted mainly through the kidney in vivo [14]; thus, there is a great possibility that they will accumulate in the kidney and further cause adverse effects such as renal fibrosis or inflammation [109, 110]. Jiang et al. [111] found that intravenously injected cadmium telluride quantum dots were mostly distributed in the kidney of mice and triggered unfolded protein response (UPR)-mediated endoplasmic reticulum autophagy, leading to renal dysfunction. In addition, mice treated with $\mathrm{ZnO}$ NPs showed renal tubular dilatation and a flattened renal tubular epithelium, and serum uric acid and creatinine levels were also significantly increased. In combination with results from an in vitro study, the authors indicated that these findings were due to excessive autophagy activation through the hypoxiainducible factor 1 (HIF-1) pathway following NP exposure [85]. This phenomenon was also confirmed in kidney exposed to $\mathrm{Fe}_{3} \mathrm{O}_{4}$ NPs, which showed other damage such as mitochondrial damage and ER stress. However, poly lactic-co-glycolic acid (PLGA) modification was found to reduce renal toxicity caused by pristine $\mathrm{Fe}_{3} \mathrm{O}_{4}$ NPs [112]. It should be noted that this finding was observed within 20 days, and PLGA may be degraded after long-term exposure to a biological environment ( $>1$ 
month); thus, it is still insufficient to draw conclusions regarding the long-term biosafety of PLGA-coated NPs in vivo.

\section{Neurotoxicity}

Autophagy plays a vital important role both in the maintenance of normal neural function but also the pathogenic mechanisms of the nervous system [113, 114]. It has been reported that nano alumina through carotid artery injection cross the blood-brain barrier to accumulate in the brain for one week, leading to local cerebral ischemia and even cerebral infarction [115]. Using the classic water maze experiment, Gao [116] found that intraperitoneal injected MWCNTs caused cognitive impairment in rats, which demonstrated decreased synaptic plasticity and hippocampal long-term potentiation (LTP). The addition of chloroquine (CQ), an autophagy inhibitor, significantly alleviated these lesions, suggesting that excessive activation of autophagy played an important role in MWCNT-induced neurotoxicity. In addition to direct exposure, maternal exposure to NMs during pregnancy might pose a safety risk to the health of offspring. Cobalt and chromium (CoCr) NPs injected via the jugular vein can reach the placenta barrier of mother rats, accumulate in the placenta, and disrupt the degradation function of autophagic flux, resulting in the release of inflammatory factor interleukin-6 (IL-6) and thus to DNA damage and abnormal differentiation of nerve progenitor cells in the brain of offspring mice [117].

\section{Cardiovascular toxicity}

By establishing exposed animal models through intratracheal instillation, inhalation, and skin contact, researchers have demonstrated that NM exposure causes cardiovascular toxicity [118-120]. It has been further reported that older rats [121] or rats with basic diseases such as hypertension [122] are more likely to develop pulmonary and cardiovascular lesions after exposure to NMs, suggesting that older people or populations with preexisting cardiovascular diseases are more sensitive to NM exposure and should be more closely monitored. At present, studies investigating the mechanism of NM-induced cardiovascular toxicity have mainly focused on the inflammatory response, oxidative stress, and mitochondrial damage [123-125]. There is evidence supporting that autophagy plays a role in regulating NM-driven cardiovascular toxicity [126]. After 14 days of intravenous injection, SiNPs resulted in increased levels of autophagosomes and LC3 and decreased expression of vascular endothelial growth factor receptor 2 (VEGFR2) in mouse heart tissue, suggesting an impaired angiogenesis capability. It was further suggested that the VEGF R2/PI3K/Akt/mTOR pathway regulated by SiNPs plays a leading role in autophagy activation and angiogenesis impairment. However, more in-depth studies are still required to investigate the regulatory mechanism of NMmediated autophagy involved in the occurrence and development of cardiovascular diseases.

At present, a growing number of studies have reported that NMs can enter the brain via peripheral nerves such as the olfactory nerve through intranasal instillation [127-129]. Interestingly, there is new evidence supporting the transport of NMs through the taste nerve pathway into the brain, but the underling mechanism remains obscure [130]. With the widespread application of NMs in food processing, their oral exposure to the human body is increasing, and more in-depth studies are required to investigate the potential neurotoxicity of NMs acquired through the oral route. Additionally, most biosafety evaluations of NMs are limited to short-term (1-30 days) exposure, while the long-term (more than 30 days) toxic effect in the body remains largely unclear. We think that confirmation of the biosafety of NMs should be based on more primarily long-term in vivo studies, which can provide reliable scientific evidence for their clinical applications.

\section{In vitro toxicity \\ Cellular uptake}

NMs can be ingested by cells in different ways, which can be divided into phagocytic and nonphagocytic pathways (described in Fig. 2). Phagocytosis is a process by which specialized phagocytes engulf particles as large as $20 \mu \mathrm{m}$, suggesting a size-dependent behavior of NMs in the biological environment. Tabei et al. [131] revealed that the toxicity of MWCNTs in human promyelocytic leukemia cells (HL-60 cells) increased with enhanced phagocytic activity, which could be repressed by treatment with the phagocytosis inhibitor cytochalasin D. Unlike specialized phagocytic cells, nonphagocytic endocytosis occurs in all cells via four major mechanisms: clathrin-mediated endocytosis (CME), caveolae-mediated endocytosis (CvME), clathrin- and caveolae-independent endocytosis, and micropinocytosis [132]. After entering cells, NMs can interact with subcellular structures and trigger a series of biological effects by mediating autophagy $[25,133,134]$.

\section{The involvement of autophagy dysfunction in organelle impairment}

Autophagy occurs and develops through a continuous dynamic process referred to as autophagic flux, which can be divided into five stages: initial, extension, autophagosome formation, autophagosome and lysosome fusion, and degradation in lysosomes [14]. Normal autophagy can remove abnormally synthesized proteins in cells and digest damaged and redundant organelles, which is beneficial for intracellular homeostasis. 


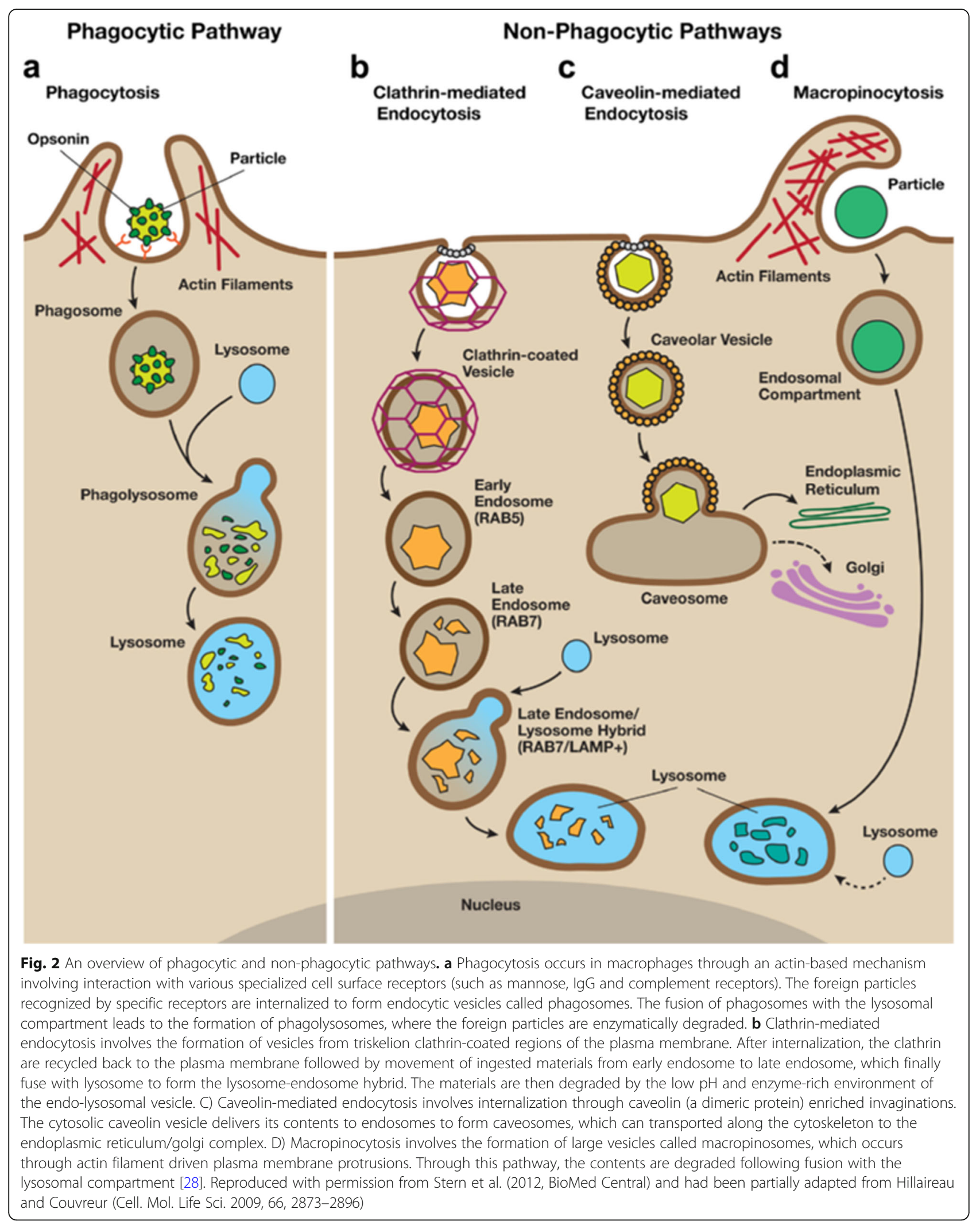


However, abnormalities in any of the above stages may lead to autophagic flux disorders and further disturb the physiological activity of the body $[135,136]$.

\section{Mitochondrial disruption}

In recent studies, mitochondrial disruption was found to be related to NM-mediated autophagy dysfunction, resulting in decreased cell viability, cellular dysfunction, or programmed cell death. For instance, fullerenolinduced mitochondrial dysfunction and cytotoxicity via excessive autophagy activation were partially alleviated by pretreatment with 3-methyladenine (3-MA), a classical autophagy inhibitor [24]. Conversely, GO-Ag NPs were detected to cause mitochondrial damage such as a decrease in mitochondrial membrane potential (MMP) in the first step, and further accelerate the progression of autophagy dysfunction [137]. Based on these results, the authors referred to mitophagy as a direct mechanism connecting mitochondrial disorder to (macro) autophagy, which can maintain mitochondrial homeostasis through clearance of damaged mitochondria and excessive superoxide anions [14]. Similar findings were also demonstrated in SiNP-treated human umbilical vein endothelial cells (HUVECs), which were manifested by decreased mitochondrial activity and membrane integrity that subsequently led to size-dependent mitophagy [138]. Mitophagy is a special type of macroautophagy in which the conditions of its occurrence and molecular regulatory mechanisms are closely related yet different from each other $[98,139]$. Whether the occurrence and development of macroautophagy and mitophagy are consistent or whether these processes are mutually inhibitory remains to be further studied.

\section{Lysosome dysfunction}

Lysosomes contain various hydrolytic enzymes and are the most important organelles in the final stage of the autophagic process. Once normal lysosomal function is impaired, autophagic flux will be disturbed to a large extent. The three main toxic mechanisms of lysosome dysfunction are as follows: lysosomal ultrastructure impairment, lysosomal overload, and lysosome alkalization. First, lysosomal membrane permeabilization (LMP) has been found to be related to NM toxicity. For instance, Wang et al. [25] found that SiNPs could increase LMP to impair the lysosomal degradative function and further disturb downstream autophagic flux in hepatocytes. Similar toxicological manifestations were also demonstrated in CNT-treated human fibroblasts [140] and cationic polystyrene nanosphere-treated human macrophages [141]. Second, lysosomal overload may result from the excessive deposition of NMs and abnormal activities of lysosomal proteases [142, 143]. Copper oxide $(\mathrm{CuO}) \mathrm{NPs}$ were prevalently deposited within lysosomes after cellular uptake, further leading to the impairment of autophagic flux by $\mathrm{Cu}^{2+}$ release in the lysosome, suggesting the important role of solubility in NP-induced toxicity [144]. Finally, lysosomal impairment is also reflected in the alkalization of lysosomes [145]. For example, larger $(50 \mathrm{~nm})$ AuNPs, not smaller (10 and 25 $\mathrm{nm})$ particles, were more likely to be internalized by cells and lead to lysosome alkalization, which weakened the lysosome degradation capacity and ultimately blocked autophagic flux [146].

\section{Endoplasmic reticulum impairment}

The endoplasmic reticulum (ER), an integral and elaborate membrane organelle, has a powerful homeostatic system to achieve ER function that includes folding and modification of secretory proteins and synthesis of cholesterol and phospholipids [147]. However, when cells are stimulated by external factors (e.g., oxidative stress and ischemia reperfusion injury), ER homeostatic imbalance may occur, leading to endoplasmic reticulum stress (ERS) [148]. Furthermore, $\mathrm{SiO}_{2}$ NP-induced ERS can further activate autophagy to reduce ER damage, a process known as ER autophagy [149]. In contrast, compared with carboxylated polystyrene (COOH-PS), $\mathrm{NH}_{2}-$ labeled polystyrene $\left(\mathrm{NH}_{2}-\mathrm{PS}\right)$ nanospheres exhibit a higher rate of cellular uptake to induce autophagy, ultimately leading to ERS and a decrease in cell activity [26]. Excessive stimulation at the initial stage of autophagy may lead to ER damage, and the blockade of autophagic flux can also accelerate the progression of ERS in magnetic iron oxide NP (M-FeNP)-treated macrophages, leading to cellular dysfunction and even cell death [133].

\section{Cytoskeleton disruption}

The cytoskeleton is an important structure by which eukaryotic cells maintain their basic morphology, including microtubules (MT), microfilaments (MF), and intermediate fibers (IF). A growing body of evidence has linked NM-induced cytoskeletal disruption with autophagy effects. Since the actin cytoskeleton participates in the formation and fusion of autophagosomes with lysosomes, any damage to the actin cytoskeleton can impair the above process, ultimately resulting in blockade of autophagic flux [126, 150]. Graphite carbon nanofibers (GCNF) can trigger apoptosis in human lung cells through excessive autophagosomes accumulation that resulted from cytoskeleton disruption-mediated autophagic flux blockade rather than autophagy induction [151]. Further evidence indicated that the impairment of the MT system, including MT clustering, fracture, and depolymerization, participated in $\mathrm{ZnO} \mathrm{NP}$-induced lysosome-autophagy system changes [152]. Therefore, MT acetylation was necessary for preventing damage to the MT structure and ensuring an intact pathway 
downstream of autophagic flux. The above two studies confirmed the important role of cytoskeleton disruption downstream of autophagy. However, does cytoskeleton damage affect processes upstream of autophagy, such as the extension and closure of double-layer membrane structures? Moreover, when autophagic flux is blocked and clearance capacity impaired, will excessive accumulation of abnormal MF and MT aggravate damage to the cytoskeleton system? Theses proposed questions still require in-depth investigations.

\section{Golgi apparatus damage}

The Golgi apparatus, a potential membrane source for autophagosome formation, is of great importance in the autophagy process. Among components of the Golgi apparatus, the seven-transmembrane, Golgi-resident protein PAQR3 has been demonstrated to function as a scaffold protein that facilitates the formation of autophagosomes [153]. However, little is known about the involvement of the Golgi apparatus in the regulation of NM-mediated autophagy, which may be due to the low probability of NM uptake by the Golgi apparatus. Interestingly, it was found that pleurotus tuber-regium (PTR)-conjugated selenium NPs (SeNPs) were distributed to the Golgi apparatus after internalization by human colon cancer cells (HCT 116 cells), and these NPs induced autophagy to promote cell apoptosis through upregulation of Beclin 1-related pathways [154]. However, whether the entry of NMs into Golgi bodies led to autophagy activation was not clarified in the study. We believe the above data suggest a functional link between the Golgi apparatus and NM-regulated autophagy, but more direct evidence is required.

\section{DNA damage}

In contrast to the above adverse effect resulting from NM-mediated autophagy, accumulating evidence suggests that autophagy is necessary for the repair process associated with the cellular response to DNA damage following NM simulation, which involves the AMPK or JNK signaling pathways $[155,156]$. For example, cerium oxide $\left(\mathrm{CeO}_{2}\right)$ NPs leads to the formation of DNA fragmentation followed by the activation of autophagy to restore DNA function, and the repair process was inhibited with the addition of 3-MA, which led to more severe DNA damage and even cell death [157]. It is worth noting that if DNA damage exceeds the repair capacity of autophagy, over-activated autophagy may aggravate the progression of DNA oxidative damage and even lead to cell death [134] .

In vitro toxicological studies of NM-mediated autophagy are summarized in Table 2. Currently, the literature is insufficient to draw conclusions about the cytotoxicity of NMs from different labs because of various factors, including the different physicochemical properties of NMs (e.g., size, functional group and solubility) and cell models. Furthermore, it is worth noting that autophagy may not only be a regulatory mechanism but also the result of other biological effects following NM exposure.

\section{The interactions between autophagy and other biological effects \\ Oxidative stress and autophagy}

The interactions of NMs with cells can lead to intracellular ROS generation, the intrinsic characteristics of which are the basic mechanisms essential for the growth or aging of organisms. However, when ROS levels exceed the activity of intracellular antioxidant enzymes, the resulting oxidative stress imbalance can induce cytotoxicity, such as apoptosis and DNA damage [18, 158, 159]. Furthermore, ROS-dependent autophagy is a widely accepted paradigm of autophagy induced by NMs. However, the role of NM-mediated autophagy is contrasting depending on different investigation models. Exposure of HUVECs to MSNPs triggered excessive autophagy via ROS-oxidative stress-mediated PI3K/Akt/ mTOR signaling that could be reversed by pretreatment with the antioxidant $\mathrm{N}$-acetyl L-cysteine (NAC), which was due to the successful activation of antioxidant enzymes [29]. Apart from treatment with antioxidants, reducing the solubility of paclitaxel NPs can decrease the production of ROS in tumor cells, thus inhibiting autophagic cell death [160]. ROS-mediated autophagic cell death was also demonstrated in SiNP-treated human hepatoma cells (HepG2 cells) and $\mathrm{TiO}_{2}$ NP-treated keratinocytes [161, 162]. Interestingly, other $\mathrm{TiO}_{2}$ NPs induced autophagy via the AMPK-mTOR signaling pathway as an antioxidant mechanism, protecting podocytes from oxidative damage and playing a pro-survival rather than a pro-death role [163]. In summary, oxidative stress may be the initial stage of toxicity of NMs, and considering that oxidative stress and autophagy regulate each other to form a positive feedback loop, an effective means to improve the biological safety of NMs is to regulate the autophagy level to maintain the oxidative stress balance.

\section{Inflammation and autophagy}

An increasing number of NMs have been demonstrated to induce significant inflammatory responses including inflammatory cell infiltration and granuloma formation [164]. Autophagy activation, as a protective mechanism against the dextran-coated $\mathrm{Fe}_{3} \mathrm{O}_{4}$ NP-induce inflammatory response, is accompanied by decreased levels of tumor necrosis factor- $\alpha$ (TNF $\alpha$ ) and IL-1 $\beta$ [165]. Similarly, both curcumin-loaded selenium NPs (Se-Cur NPs) [166] and MSNs [167] are able to evoke autophagy and attenuate the inflammatory effect mediated by the NF- 
Table 2 In vitro toxicological studies of NPs mediated autophagy

\begin{tabular}{|c|c|c|c|c|c|c|c|c|}
\hline NPs & Size $(n m)$ & Coating & Cell line & Dose(ug/mL) & Uptake & $\begin{array}{l}\text { Autophagy } \\
\text { alteration }\end{array}$ & Biological effects & References \\
\hline Fullerenol & 2 & bare & $\begin{array}{l}\text { porcine renal } \\
\text { proximal } \\
\text { cells }\end{array}$ & $0.1,1,10 \mathrm{nM}$ & - & $\begin{array}{l}\text { induction of } \\
\text { autophagy } \\
\text { autolysosome } \\
\text { accumulation, } \\
\text { LC3 } \uparrow\end{array}$ & $\begin{array}{l}\text { mitochondrial } \\
\text { membrane potential } \\
\text { and ATP depletion, } \\
\text { oxidative stress, } \\
\text { cytoskeleton } \\
\text { disruption, cell death }\end{array}$ & {$[24]$} \\
\hline SiNPS & $\sim 58.4 \pm 7.4$ & bare & HepG2 cells & $\begin{array}{l}6.25,12.5 \\
25,50,100\end{array}$ & endocytose & $\begin{array}{l}\text { induction of } \\
\text { autophagy and } \\
\text { blockade of } \\
\text { autophagic flux } \\
\text { autophagosome } \\
\text { accumulation, } \\
\text { LC3 } \uparrow, \text { P62 } \uparrow\end{array}$ & $\begin{array}{l}\text { impaired the } \\
\text { lysosomal function }\end{array}$ & [29] \\
\hline $\mathrm{GO}$ & $500-800$ & bare & PC12 cells & $40,50,60$ & internalization & $\begin{array}{l}\text { blockage of the } \\
\text { autophagic flux, } \\
\text { p62 } \uparrow\end{array}$ & $\begin{array}{l}\text { Impairment of } \\
\text { lysosomal } \\
\text { degradation } \\
\text { Apoptosis }\end{array}$ & {$[31]$} \\
\hline CdTe-QDs & 15 & bare & HEK cells & $\begin{array}{l}15,30,60 \\
\mathrm{nM}\end{array}$ & endocytosis & $\begin{array}{l}\text { induction of } \\
\text { autophagy, LC3 } \uparrow\end{array}$ & $\begin{array}{l}\text { ER autophagy, } \\
\text { unfolded protein } \\
\text { response }\end{array}$ & {$[88]$} \\
\hline $\mathrm{Fe}_{3} \mathrm{O}_{4} \mathrm{NPs}$ & $15 \sim 20$ & bare & MCF-7 cells & 100 & endocytosis & $\begin{array}{l}\text { induction of } \\
\text { autophagy } \\
\text { autophagosome } \\
\text { accumulation }\end{array}$ & $\begin{array}{l}\text { impair the function of } \\
\text { the lysosome, } \\
\text { mitochondrial } \\
\text { damage, ER and Golgi } \\
\text { stress }\end{array}$ & [89] \\
\hline GO-Ag NPs & 15 & bare & SH-SY5Y cells & 5 & - & $\begin{array}{l}\text { induction of } \\
\text { autophagy } \\
\text { autophagosomes } \\
\text { accumulation }\end{array}$ & $\begin{array}{l}\text { mitichondrial } \\
\text { dysfunction, ROS, } \\
\text { DNA fragmentation, } \\
\text { apoptosis }\end{array}$ & {$[137]$} \\
\hline $\mathrm{TiO}_{2} \mathrm{NPS}$ & $15,50,100$ & bare & HeLa cells & $\begin{array}{l}10,50,100 \\
500\end{array}$ & internalization & $\begin{array}{l}\text { blockage of the } \\
\text { autophagic flux, } \\
\text { LC3 } \uparrow\end{array}$ & $\begin{array}{l}\text { lysosomal membrane } \\
\text { permeabilization, } \\
\text { a-synuclein } \\
\text { accumulation }\end{array}$ & [139] \\
\hline GQDs & $3.28 \pm 1.16$ & barre & $\begin{array}{l}\text { GC- }-2 \text { cells } \\
\text { TM-4 cells }\end{array}$ & 100 & - & $\begin{array}{l}\text { blockade of } \\
\text { autophagic flux } \\
\text { autophagosome } \\
\text { accumulation p62 } \\
\uparrow\end{array}$ & $\begin{array}{l}\text { decreased the } \\
\text { amount and } \\
\text { enzymatic activity of } \\
\text { cathepsin B, and } \\
\text { inhibited lysosome } \\
\text { proteolytic capacity }\end{array}$ & [142] \\
\hline AuNPs & $10,25,50$ & bare & NRK cells & $1 \mathrm{nM}$ & endocytosis & $\begin{array}{l}\text { blockade of } \\
\text { autophagic flux } \\
\text { autophagosome } \\
\text { accumulation, } \\
\text { LC3 } \uparrow, \text { p62 } \uparrow\end{array}$ & $\begin{array}{l}\text { Impairment of } \\
\text { lysosome degradation } \\
\text { capacity, Lysosome } \\
\text { alkalinization }\end{array}$ & [146] \\
\hline $\mathrm{HA} / \beta-\mathrm{Ga}_{2} \mathrm{O}_{3}: \mathrm{Cr}^{3+} \mathrm{NPS}$ & - & bare & SH-SY5Y cells & $1,5,25,50$ & - & $\begin{array}{l}\text { induction of } \\
\text { autophagy, } \\
\text { LC3 } \uparrow \text {, SQSTM/ } \\
\text { p62 } \uparrow\end{array}$ & $\begin{array}{l}\text { ROS, calpain } \\
\text { activation and } \\
\text { neuronal damage }\end{array}$ & [150] \\
\hline GCNs & $\begin{array}{l}\text { outer } \\
\text { diameter of } \\
79 \pm 6.6, \text { inner } \\
\text { diameter of } \\
7 \pm 0.8\end{array}$ & bare & A549 cells & $\begin{array}{l}1,10,25,50 \\
100\end{array}$ & endocytosis & $\begin{array}{l}\text { blockage of } \\
\text { autophagic flux } \\
\text { autolysosome } \\
\text { accumulation }\end{array}$ & $\begin{array}{l}\text { ROS, cytoskeleton } \\
\text { disruption, apoptosis }\end{array}$ & [151] \\
\hline SeNPs & $80.0 \pm 12.3 \mathrm{~nm}$ & bare & $\begin{array}{l}\text { HCT } 116 \\
\text { cells }\end{array}$ & $2,5,10 \mu \mathrm{M}$ & endocytosis & $\begin{array}{l}\text { induction of } \\
\text { autophagy, } \\
\text { Beclin } 1 \uparrow\end{array}$ & $\begin{array}{l}\text { cell cycle arrest, } \\
\text { apoptosis }\end{array}$ & [154] \\
\hline $\mathrm{TiO}_{2} \mathrm{NPs}$ & $22.07 \pm 8.93$ & bare & BEAS-2B cells & $6.25,12.5,25$ & internalization & $\begin{array}{l}\text { induction of } \\
\text { autophagy } \\
\text { accumulation of } \\
\text { autophagic } \\
\text { vacuoles, LC3 } \uparrow\end{array}$ & $\begin{array}{l}\text { overexpressed } \\
\text { miR34a, mitochondrial } \\
\text { dysfunction, cell } \\
\text { death }\end{array}$ & [158] \\
\hline
\end{tabular}


Table 2 In vitro toxicological studies of NPs mediated autophagy (Continued)

\begin{tabular}{|c|c|c|c|c|c|c|c|c|}
\hline NPs & Size $(n m)$ & Coating & Cell line & Dose(ug/mL) & Uptake & $\begin{array}{l}\text { Autophagy } \\
\text { alteration }\end{array}$ & Biological effects & References \\
\hline PU NPS & $64.3 \pm 0.8$ & Carboxyl & $\begin{array}{l}\text { macrophage } \\
\text { cells }\end{array}$ & 10,50 & internalization & $\begin{array}{l}\text { Induction of } \\
\text { autophagy }\end{array}$ & $\begin{array}{l}\text { Inhibition of } \\
\text { inflammation and } \\
\text { immune supression }\end{array}$ & [159] \\
\hline SPIONS & $60-80$ & bare & $\begin{array}{l}\text { Raw264.7 } \\
\text { cells } \\
\text { BMDMs }\end{array}$ & $10,20,50,100$ & endocytosis & $\begin{array}{l}\text { Induction of } \\
\text { autophagy } \\
\text { autophagosomes } \\
\text { accumulation, } \\
\text { LC3 } \uparrow \text {, ATG } \uparrow\end{array}$ & $\begin{array}{l}\text { Inflammatory } \\
\text { responses }\end{array}$ & [160] \\
\hline \multirow[t]{2}{*}{ GO } & $\begin{array}{l}\text { MGO: } \\
1089.9 \pm 135.3 \\
\text { SGO: } 390.2 \pm \\
51.4 \\
\text { NGO:65.5 } \pm \\
16.3 \\
\text { GQDs:5 }\end{array}$ & bare & HUVECS & $1,5,10,25$ & internalization & $\begin{array}{l}\text { induction of } \\
\text { autophagy, } \\
\text { LC3 } \uparrow \text { p62 } \downarrow\end{array}$ & $\begin{array}{l}\text { Apoptosis, Apoptotic } \\
\text { cell death, ER stress }\end{array}$ & [161] \\
\hline & $127 \pm 4.7$ & PEG. & $\begin{array}{l}\text { MCF7 cells } \\
\text { MDA-MB- } 231 \\
\text { cells }\end{array}$ & 4 & - & $\begin{array}{l}\text { inhibition of } \\
\text { autophagy, } \\
\text { LC3 } \downarrow\end{array}$ & $\begin{array}{l}\text { apoptosis, suppressed } \\
\text { Stathmin1 protein, } \\
\text { decreases the } \\
\text { microtubule } \\
\text { instability, cancer cell } \\
\text { death }\end{array}$ & [162] \\
\hline
\end{tabular}

кB signaling pathway. Upon autophagy deactivation, polyurethane NPs (PU NPs) also reduces the death rate by inhibiting the recruitment of macrophages and monocytes [168]. Furthermore, unmodified $\mathrm{Fe}_{3} \mathrm{O}_{4}$ NPs can lead to endothelial dysfunction and inflammation by excessive autophagy induction that may be highly associated with the Beclin-1/VPS34 complex [19]. Superparamagnetic iron oxide NPs (SPIONs) trigger toll-like receptor-4 (TLR-4)-dependent autophagy, which promotes the phosphorylation of p38 and nuclear translocation of Nrf2, finally leading to the upregulation of p62/ SQSTM and inflammatory response [169]. NP-induced autophagy is crucial for NP metabolism and cytotoxicity, but there have been insufficient studies on how the host immune system responds to NP-induced autophagy. Considering that certain inflammatory diseases such as psoriasis and lamellar ichthyosis are associated with autophagy [170], it is necessary to identify more molecular targets of autophagy and inflammation and use characteristics of NM-regulated autophagy to treat inflammation-related diseases.

\section{Apoptosis and autophagy}

Apoptosis, as a type of programmed cell death, features cell shrinkage, membrane blebbing, internucleosomal DNA fragmentation, chromatin condensation, and the formation of apoptotic bodies [171]. The crosstalk between apoptosis and autophagy has been confirmed in various studies of NMs. For example, ZnO NPs cause excessive autophagy via inhibiting the PI3K/Akt/mTOR signaling pathway, leading to cell apoptosis manifested by the cleavage of the apoptosis markers caspase 3 , caspase 8 , and caspase 9 [20]. $\mathrm{CeO}_{2}$ NPs can trigger autophagy at relatively low doses (5 or $10 \mu \mathrm{g} / \mathrm{mL}$ ), and the subsequent activation and relocation of Bax to the mitochondria were followed by mitochondrial-dependent apoptosis [27]. Additionally, our previous research has demonstrated that GO can impair autophagic flux through the alkalization of lysosomes, eventually resulting in p62/SQSTM-dependent apoptosis, as confirmed by caspase $3 / 9$ activation [31]. GO was also shown to induce autophagy via c-Jun N-terminal kinase (JNK)-mediated phosphorylation of B-cell lymphoma 2 (Bcl-2), accompanied by the dissociation of the Beclin-1/Bcl-2 complex, prompting the execution of apoptosis [172]. In conclusion, the initiation of autophagy leads to the inactivation of antiapoptotic proteins, and autophagic flux impairment leads to the accumulation of autophagy substrates that primarily trigger apoptosis directly mediated by the endogenous mitochondrial pathway, suggesting that mitochondria are the pivotal intermediate link between autophagy and apoptotic effects.

\section{Necroptosis and autophagy}

Necroptosis, which is known as "programmed necrosis", is critically regulated by receptor interaction protein kinase 1 and 3 (RIP1 and RIP3 respectively) and plays an important role in immune system regulation, tissue injury, and cancer development [173-175]. Furthermore, autophagy and necroptosis may influence each other and form a positive feedback loop, promoting the process of cell death in nano-toxicology studies. The anticancer 
agent graphene oxide-chloroquine (GO-CQ) nanoconjugate was designed to induce the accumulation of autophagosomes through the blockade of autophagic flux, which served as a scaffold for necrosome assembly in human lung adenocarcinoma cells (A549 cells), leading to cell necroptosis [33]. In turn, hyaluronic acid-modified NPs loaded with CQ significantly upregulated RIP3 expression, subsequently interrupting autophagic flux via LMP, leading to autophagic cell death [25]. Little is known about the regulatory mechanism between autophagy and necroptosis, but autophagosomes may be upstream or downstream targets of the RIP1/RIP3 complex. Additionally, functionalized NMs can be designed as an effective therapeutic agent by their targeting of the autophagy-necroptosis axis.

\section{Epigenetic alteration and autophagy}

Epigenetic phenomena are numerous, including DNA methylation, genomic imprinting, maternal effects, gene silencing, nucleolus dominance, dormant transposon activation, and RNA editing [176]. MicroRNAs (miRNAs), a form of non-coding RNA, can regulate autophagy effects involved in the occurrence and development of cancer. Based on the unique physical and chemical properties of NMs, the present research focused on how to combine nanocarriers to improve the biological stability of miRNAs because they are susceptible to acidic degradation and deactivation inside endosomes and lysosomes [177, 178]. The cationic GO nanoplatform, an efficient targeted delivery system for the transfection of human breast cancer cells (MCF7 cells) with miR-101, has been shown to downregulate autophagy and subsequently contributes to $68 \%$ apoptosis [179]. Conversely, chitosan NPs used as carriers for miRNA 34a inhibit the growth of prostate cancer cells by inducing noncanonical autophagy via a proapoptotic effect [180].

DNA methylation is one of the most important epigenetic modulators, alterations of which are attracting growing attention as an underlying molecular target of NMs toxicity [181, 182]. In addition, DNA methylation may upregulate cell autophagy to reduce the sensitivity of hepatoma cells to chemotherapy or promote the development of diabetes due to the deacetylation of autophagy-related proteins [183, 184]. Given that DNA methylation is associated with the above diseases, further study of the relationship between NMs and DNA methylation provides a new way to evaluate the biocompatibility of NMs. Moreover, autophagy may act as a downstream mechanism of epigenetic changes and work together to regulate cell survival to promote the effects of nanotherapy.

\section{Others}

Pyroptosis is a type of proinflammatory programmed cell death featuring gasdermin family-mediated membrane pore formation and cell lysis, accompanied by the release of proinflammatory contents [185]. Various NMs have been shown to cause pyroptosis, mainly regulated by caspase-1 signaling pathways [186-188]. Molecules upstream of the caspase-1 signaling pathway involve the NLRP3 inflammatory complex, including cathepsin B, mitochondrial reactive oxygen species (mtROS), and mitochondrial DNA (mtDNA) [189, 190]. Conversely, strong autophagy induced by adrenomedullin via the ROS-AMPK-mTOR signaling pathway can alleviate the pyroptosis of Leydig cells; similar effects were observed for galangin-treated glioblastoma multiforme, suggesting that autophagy may initially serve as a protective mechanism to prevent pyroptosis [191, 192]. Studies on the relationship between autophagy mediated by NMs and pyroptosis are insufficient. As mitophagy dysfunction is related to the generation of mtROS and mtDNA [193], which can trigger caspase1-dependent pyroptosis [188, 189], we speculate that the mitophagy dysfunction caused by NMs may be associated with pyroptosis, meriting further study. Therefore, the use of NMs to activate autophagy may be an efficient strategy to treat clinical diseases related to pyroptosis, such as diabetic cardiomyopathy, infectious diseases, and atherosclerosis [194-196].

Ferroptosis is a new form of regulated cell death (RCD) that mainly relies on iron accumulation and lipid peroxidation [29, 197] Furthermore, functionalized NPs have been shown to induce ferroptosis in cancer cells presumably due to pronounced lipid peroxidation and depletion of glutathione [198, 199]. However, a high level of ferroptosis not only kills cancer cells but also causes tissue injury. Considering that induction of autophagy contributes to ferroptosis, how lipid peroxidation affects autophagosome formation or degradation as feedback loops and how NMs play an upstream regulatory role in the autophagyferroptosis axis may be directions worth further investigating. Figure 3 shows the intracellular interactions between NM-mediated autophagy and other biological effects.

\section{Possible therapies related to NM-mediated autophagy}

Because autophagy dysfunction plays a key role in the occurrence of diseases, we can utilize NPs that either induce or inhibit autophagy to restore cellular homeostasis in the body and even cure diseases (Table 3). For instance, cytoprotective autophagy has advantageous effects on sick cells. Cytotoxic autophagy can result in the direct clearance of cancerous cells or make them susceptible to chemotherapy drugs, which is beneficial for the treatment of clinical disease. Thus, it is crucial to comprehend the precise mechanism by which the autophagic process is involved in corresponding disorders. 


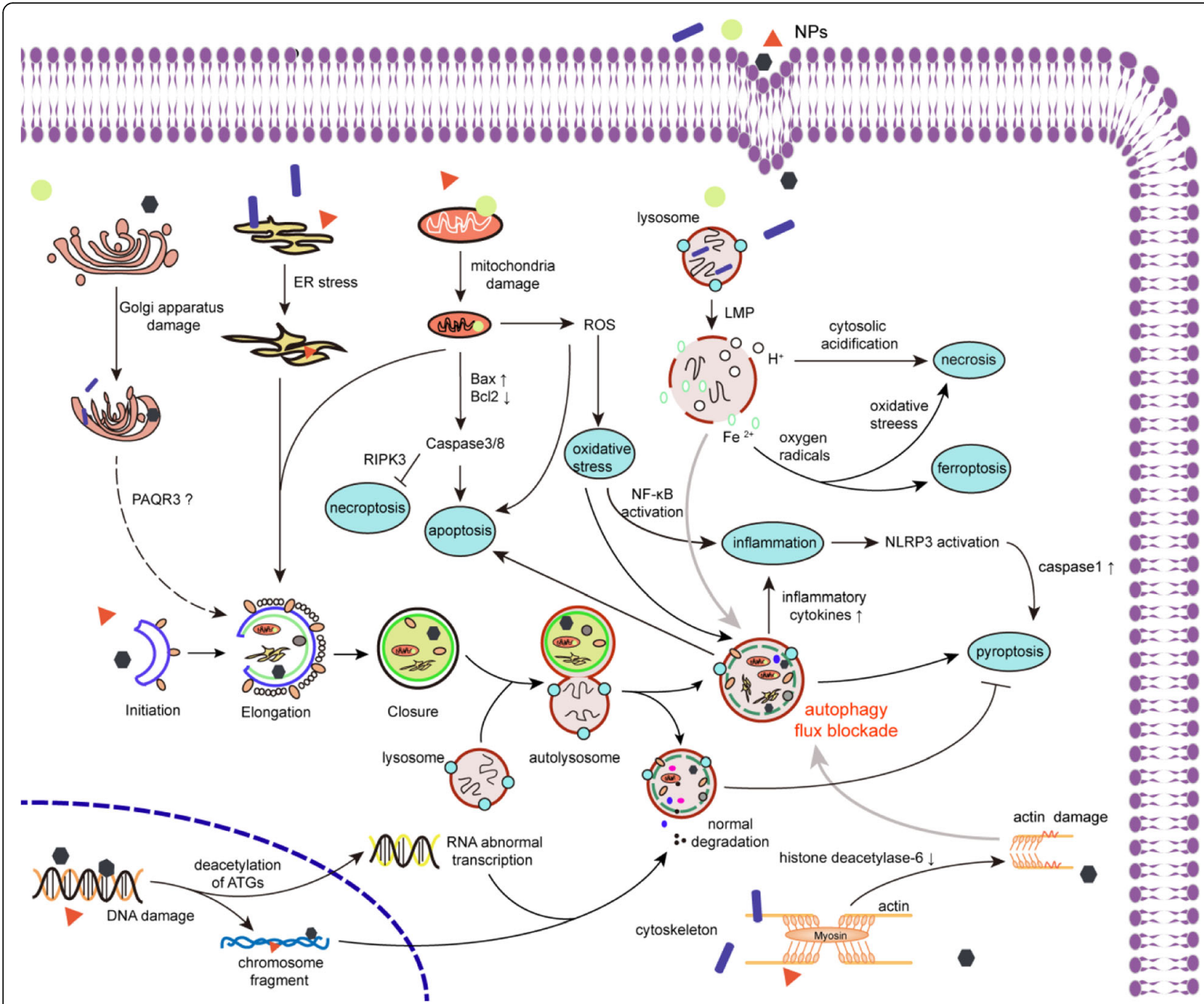

Fig. 3 The interactions between NM-mediated autophagy and other biological effects. NMs endocytosed into cells can impaire various organelles including golgi apparatus, endoplasmic reticulum, mitochondria and lysosomes. The damaged organelles are sequestered by primary autophagosomes, which are fused with lysosomes to form autolysosomes, leading to degradation or autophagic flux blockade occur. Autophagy dysfunction will further cause cell inflammation, oxidative stress, apoptosis and pyroptosis. NMs induced LMP can result in cytoplasmic acidification and release of $\mathrm{Fe}^{2+}$, which directly relate to autophagic flux blockage and further cell necrosis. The mitophagy dysfunction can lead to caspase 8 activation, which can inhibit the expression of RIPK3, thereby inhibiting necroptosis. NMs cause RNA damage through the deacetylation of autophagy-related proteins and DNA damage through accumulation of chromosome fragments, both activating the autophagy pathway. Impairment of cytoskeleton is mainly manifested by the damage of actin and the decreased expression of histone deacetylase-6, which eventually leads to the disorder of autophagic flux

\section{Anticancer therapy}

\section{Autophagy preference in cancerous cells}

It has been proposed that autophagy activity in tumor cells is higher than in normal cells, which may be related to the higher sensitivity of tumor cells toward oxidative stress [200, 201]. For example, 2-methoxyestradiol (2-ME) could kill leukemia cells rather than normal lymphocytes by causing the production of ROS, an effect that was further confirmed to be associated with excessive autophagy [202]. Compared with normal mouse astrocytes, the treatment of cancer cells with $\mathrm{H}_{2} \mathrm{O}_{2}$ exerted marked autophagy activation and decreased cell viability [203]. Additionally, cancer cells require higher levels of ATP by mitochondria to maintain their rapid proliferation and elevated metabolism. Any mitochondrial damage might therefore result in autophagy induction more rapidly than noncancerous cells [204]. The above data provide a theoretical basis for selective induction of autophagy in cancer cells. 


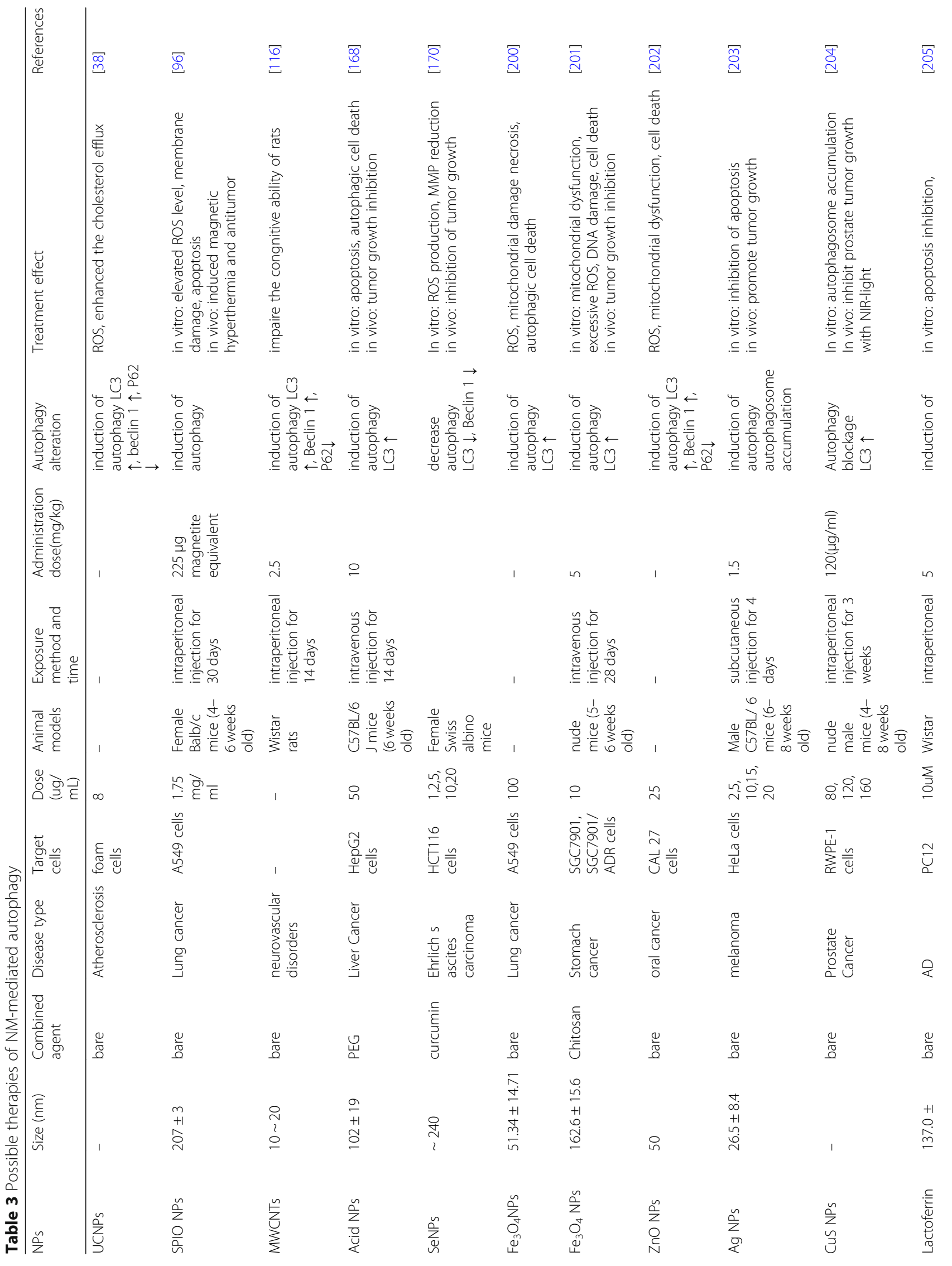




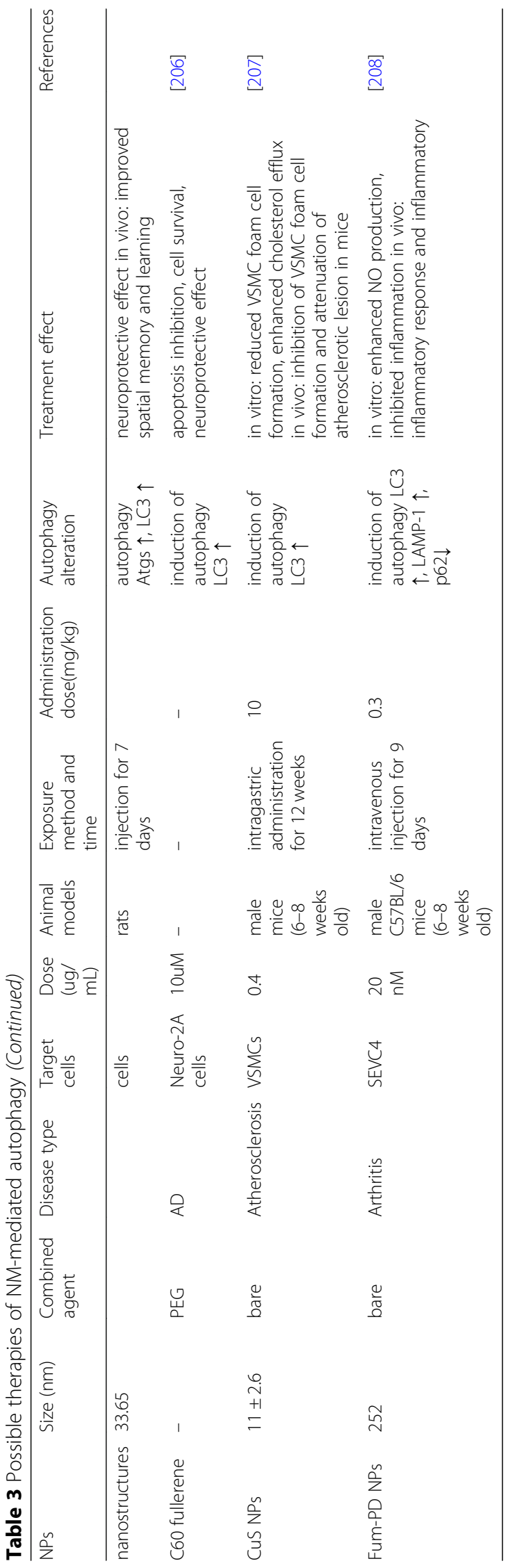




\section{(A) Autophagy as tumor suppressor}

(1) Functional autophagy

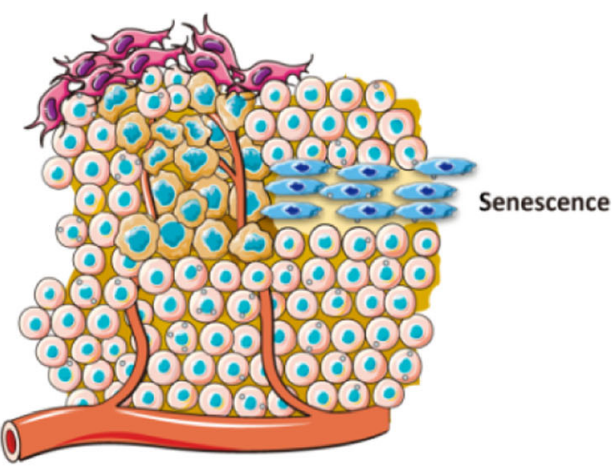

- $\uparrow$ Quality control

- $\uparrow$ Senescence

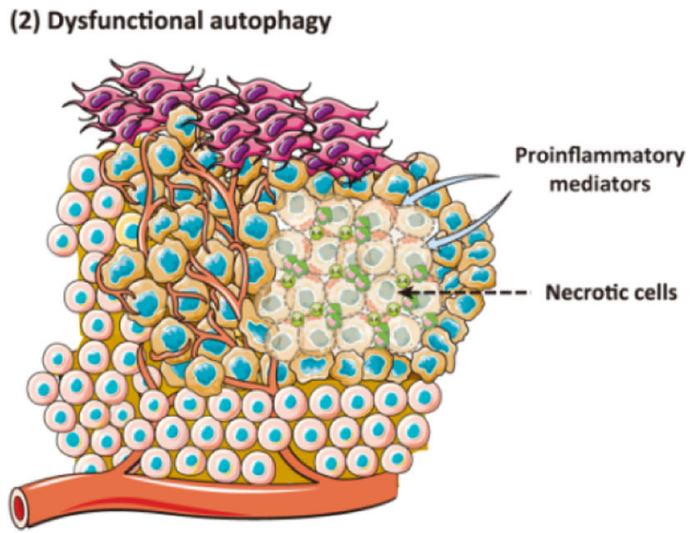

- IROS production, I mitochondrial and DNA damage, † genomic instability

- †p62 accumulation, $\uparrow$ protein-aggregates accumulation, $\uparrow \mathrm{Nrf2}$-ARE activity, proinflammatory NF- $\mathrm{B}$ s signaling, †IL-6 production

- IMacrophages infiltration

- † Necrosis, when apoptosis is compromised

(B) Autophagy as tumor promoter

(1) Functional autophagy

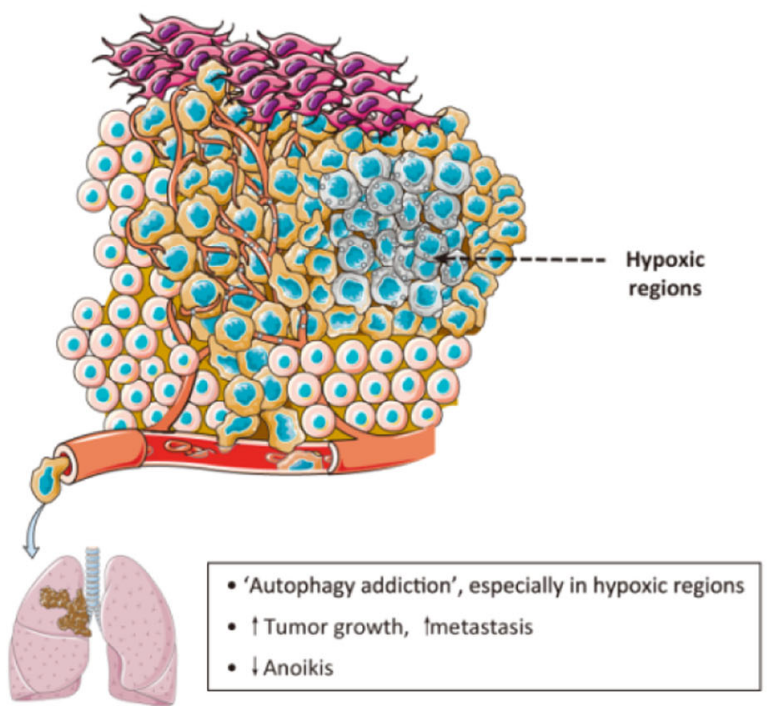

(2) Dysfunctional autophagy

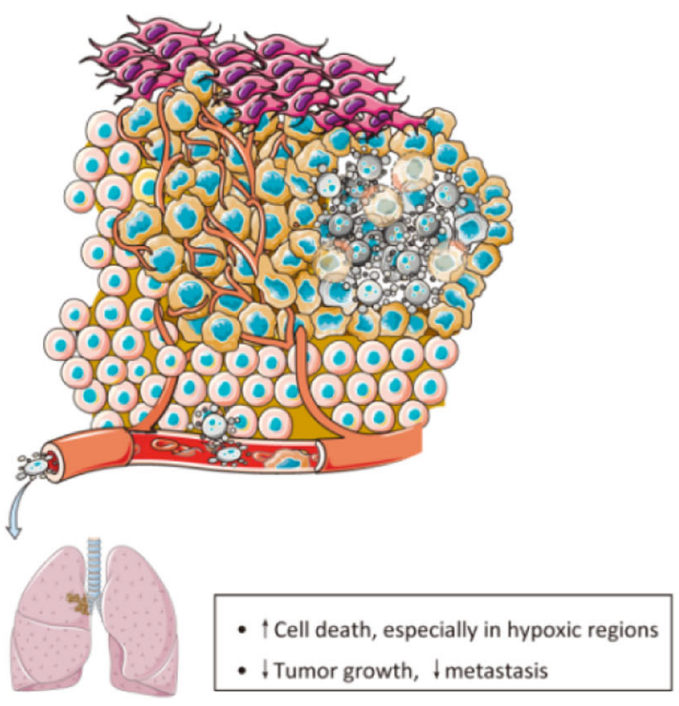

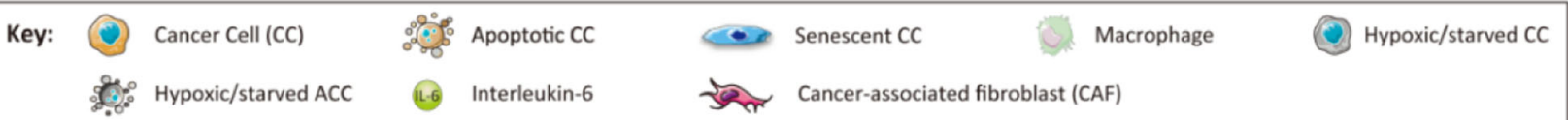

Fig. 4 Dual role of cancer cell-associated autophagy in cancer progression. This figure depicts recently described mechanisms supporting a tumor suppressor or tumor promoter role for autophagy. a Autophagy as tumor suppressor mechanism. (1) Functional autophagy acts as a quality control mechanism that, under stressed conditions, either restores homeostasis or induces senescence, thus preventing tumorigenesis. (2) Genomic instability, chronic inflammation, p62 accumulation, or increased inflammation associated with tumor initiation and progression under conditions of defective autophagy support a tumor suppressor role for autophagy in cancer progression. b Autophagy as tumor promoter mechanism. (1) 'Autophagy addiction', especially observed in hypoxic regions of solid tumors, and decreased anoikis help sustain cancer cell viability by promoting malignant growth and metastasis. (2) The increased cancer cell death, especially in hypoxic regions, and reduction of tumor growth and metastasis observed under conditions of autophagy defects indicate that autophagy is a tumor-promoting mechanism in solid tumors [206]. Copyright (2013), with permission from Elsevier 


\section{Dual role of autophagy in tumor progression}

In early-stage tumors (dysplastic stage), autophagy acts as a tumor suppressor to eliminate certain harmful substances and conserve cell homeostasis. For instance, in liver cancer at the dysplastic stage, autophagy was able to slow tumor formation by reducing ROS production, DNA damage, and the release of inflammatory cytokines [204]. Knockout of key autophagy-related genes promoted tumorigenesis, as confirmed by the development of a variety of malignant tumors in Becn $1^{+/-}$mice. The authors further demonstrated that autophagy could limit the expression of B-cell CLL/lymphoma 10 (BCL10), ultimately inhibiting the formation of an NF- $\mathrm{kB}$ signaling pathwayregulated inflammatory microenvironment [183]. At the genetic level, autophagy inhibition can aggravate DNA damage, leading to DNA mutation accumulation and genomic instability, which may contribute to transformation from a normal to a cancerous cell [205].

Autophagy may act as a prosurvival mechanism in established tumors, which can degrade damaged proteins and consume ROS [206, 207]. The difficulties in clinical antitumor treatment lie in reducing the autophagic activity of tumor cells and improving the sensitivity of chemotherapy drugs. A study of gastric cancer (GC) cells showed that the autophagy pathway was easily activated through inhibiting PI3K/mTOR expression to resist drug sensitivity [208]. Additionally, increased autophagic flux was beneficial for mammary cancer progression through the promotion of mitophagy and maintenance of redox homeostasis; excessive accumulation of damaged mitochondria and ROS were thus avoided [209]. Consistent with these data, p62 has been shown to support tumor progression through the activation of a variety of transcription factors including Nrf2 [210].. The dual role of autophagy in tumor progression is illustrated in Fig. 4.

\section{Selective killing of cancer cells}

Autophagy induction as a method in cancer therapy based on the potential benefits of selectively killing cancer cells without (or minimally) impairing noncancerous cells has received increasing attention. For instance, two types of iron oxide NMs can induce autophagy in cancer cells to exert anti-tumor effects, among which ROS were an important intermediate, and there was no significant change in normal cell viability $[211,212]$. ZnO NPtreated oral cancer cells (CAL27 cells) showed significant decreases in cell viability via PINK1/Parkin-regulated mitophagy [213]. Another TLR-4/TLR-9 signaling cascade was involved in the GO-induced autophagy process, which inhibited the growth of colon cancer cells (CT26 cells) [214]. These findings suggest that autophagy removes substances needed for tumor cell growth and creates a microenvironment that is not suitable for tumor growth, such as ATP deficiency and a balanced redox system.

When autophagy acts as a prosurvival pathway for cancer cells, the inhibition of autophagy by NMs is beneficial for killing tumor cells. For example, polyethyleneimine (PEI)-coated iron oxide NPs (IONPs) exhibits high uptake in cancer cells, resulting in excessive ROS production and subsequent apoptosis through inhibiting autophagy in a dose-dependent manner [215]. Apart from functionalization of NMs, the addition of the autophagy inhibitor wortmannin or CQ can increase the anticancer effect of AgNPs and copper sulfide (CuS) nanoplates in malignant tumor cells through decreasing autophagy activity $[216,217]$. It is worth noting that two research complications must be solved in the future. First, how can we distinguish the different roles of autophagy in tumorigenesis (promoting or inhibiting tumor survival)? Second, how can we control the autophagy level of NMs to avoid damage to normal cells?

\section{Treatment of diseases in the CNS}

The primary cause of most neurodegenerative diseases, including Alzheimer's disease (AD) and Parkinson's disease (PD), is autophagy deficiency, making the targeted induction of autophagy a pivotal aim for their treatment. However, excessive autophagy activation can also lead to nerve damage, and therefore, preserving moderate autophagy levels is essential for maintaining normal nerve function.

\section{Autophagy and neurodegenerative disease}

$\mathrm{AD}$ and $\mathrm{PD}$ are characterized by amyloid beta $(\mathrm{A} \beta)$ plaque accumulation in the hippocampus/cerebral cortex regions and aberrant $\alpha$-synuclein proteins in the striatal region, respectively [218]. In these diseases, downregulation of autophagy was thought to prevent the degradation of these aggregates, leading to their significant accumulation within the cell. Komatsu et al. [113] found that mice lacking Atg7 protein showed significant neurodegeneration and behavioral deficits. Similarly, autophagy dysfunction caused by abnormal mTOR signaling pathway was shown to contribute to parkinsonian changes in mice [219]. Considering that pretreatment of mice with the autophagy inducer rapamycin can reverse the above abnormal behavior by reducing the accumulation of abnormal protein plaques $[220,221]$, it is valuable to exploit NP-induced autophagy to cure neurodegenerative disease.

For example, lactoferrin-conjugated nanostructures have been reported to restore cognitive deficits in rats through autophagy induction and interfere with the apoptotic caspase cascade in rat pheochromocytoma cells (PC12 cells) [222]. Fullerene-based NMs can activate autophagy as a defense mechanism against $A \beta$ dependent neurotoxic effects, such as decreasing ROS 
generation and maintaining MMP [223]. In the treatment of PD, PLGA acidic NPs can restore autophagy activity to its basal level by enhancing lysosomal degradation functions such as normalizing lysosomal $\mathrm{pH}$, thereby facilitating the removal of damaged or abnormal proteins [224]. The targets of autophagy defects in each disease are different, so it is necessary to identify the regulatory autophagy targets in different diseases to improve therapeutic effects.

\section{Autophagy and nerve injury}

Studies have demonstrated that excessive autophagy activation plays an important role in the pathological development of permanent cerebral ischemia and neurotoxicity of iodine $[225,226]$. In an in vitro study, after knockdown of LC3 or Atg7, neuritic degeneration caused by axon injury was decreased, whereas the autophagy inducer rapamycin potentiated these effects [227]. In addition, Purkinje cell axons in an animal model of inherited ataxias frequently contained a large number of autophagosomes and autophagosome-like vacuoles, which could result in Purkinje cell degeneration, suggesting neurotoxic effects of excessive autophagy [228]. However, recent studies on the utilization of NMs for the treatment of autophagy-induced nerve injury are still insufficient, and more thorough studies are required.

\section{Treatment of cardiovascular disease}

Atherosclerosis is a chronic inflammatory cardiovascular disease. Macrophage-derived foam cells are a major component of atherosclerotic plaques, and with the development of the lesion, the center of the atherosclerotic plaque becomes necrotic [229]. Regarding photodynamic therapy (PDT), upconversion fluorescent NPs significantly induce autophagy in foam cells, leading to cholesterol efflux and preventing the maturation of atherosclerotic plaques [38]. A recent study found that $\mathrm{CuS}$ NP-treated vascular smooth muscle cells (VSMCs) were able to stimulate $\mathrm{Ca}^{2+}$ influx, followed by autophagy activation to impede foam cell formation [230]. From the perspective of blocking downstream autophagic flux, AgNPs can inhibit the differentiation of monocyte-macrophages by impairing lysosomal function, suggesting prevention of the occurrence of earlier cardiovascular disease [231]. Considering the differences in the pathogenesis of atherosclerosis at different developmental stages, a more reliable animal model should be established to systematically analyze the molecular targets associated with NM-mediated autophagy for a better treatment effect.

\section{Other potential therapies}

In addition to the widespread attention paid to the nano-therapy of cancer and neurodegenerative diseases, there have been increasing reports on the occurrence and development of immune system disorders and osteoarthropathy, which are closely related to autophagy disorders. For example, MWCNTs were able to downregulate autophagy of $\mathrm{T}$ and $\mathrm{B}$ cells to its basal level, restoring the autoimmune condition and alleviating the pathological progression of systemic lupus erythematosus (SLE) [37]. In comparison, in the treatment of rheumatoid arthritis (RA), fumagillin prodrug (Fum-PD) NPs can promote autophagic flux, followed by inhibition of the NF- $\kappa B$ signaling pathway-dependent inflammatory response [232]. Additionally, based on the significant effectiveness of anti-ROS therapy, dopamine melanin NPs were utilized to further decelerate cartilage degradation through autophagy activation for efficient treatment of osteoarthritis (OA) [233]. Subsequently, the targeted regulation of autophagy by using direct NMs or as drug carriers has introduce huge potential for clinical treatment of related diseases. However, additional work is still required concerning how to reduce the existing adverse effects of NM-induced autophagy.

\section{Conclusion and outlook (the dual role of NM-mediated autophagy in biomedicine)}

This review has summarized research progress addressing potential hazards and beneficial effects of NM-mediated autophagy in biomedicine. First, the wide applications of NMs in biomedicine (including drug delivery systems, tissue engineering, biosensors, and bioimaging system) have led to growing exposure risks of the human body to NMs and their composites. Thus, potential in vivo and in vitro toxic manifestations related to NM-mediated autophagy and mechanisms of action contributing to these adverse effects are discussed. Conversely, it is worth noting that the interactions between autophagy and other biological effects following NM exposure are complicated; thus, NM-mediated autophagy can serve a dual role in biomedicine. Although some of the regulatory process remains unclear, it has shown great potential to exploit NMs to regulate autophagy in the treatment of related clinical diseases, including cancer, neurodegenerative, and cardiovascular diseases. Currently, as autophagy is a multi-factor regulatory process affected by different physicochemical properties of NMs and varying animal or cell models, the data are insufficient to draw conclusions about the influence of NM-regulated autophagy on human health. This review will serve as an important step in understanding the dual role of NMmediated autophagy and further promoting their beneficial applications in the field of biomedicine.

\section{Abbreviations}

Aß: Amyloid beta; AD: Alzheimer's disease; AgNPs: Silver NPs; ALT: Alanine aminotransferase; AST: Aspartate aminotransferase; Atg: Autophagy-related protein; AuNPs: Gold NPs; A549 cells: Human lung adenocarcinoma cells; Bcl2: B-cell lymphoma 2; BCL10: B-cell CLL/lymphoma 10; CAL27 cells: Oral 
cancer cells; $\mathrm{CeO}_{2}$ : Cerium dioxide; CME: Clathrin-mediated endocytosis; CNTs: Carbon nanotubes; CoCr: Cobalt and Chromium; $\mathrm{COOH}-$ PS: Carboxylated polystyrene; CQ: Chloroquine; CTAB: Cetyl trimethylammonium bromide; CT26 cells: Colon cancer cells; CuO: Copper oxide; CuS: Copper sulfide; CvME: Caveolae-mediated endocytosis; ER: Endoplasmic reticulum; ERS: Endoplasmic reticulum stress; $\mathrm{Fe}_{2} \mathrm{O}_{3}$ : Iron oxide; $\mathrm{Fe}_{3} \mathrm{O}_{4}$ : Ferrosoferric oxide; Fum-PD: Fumagillin prodrug; GC: Gastric cancer; GCNF: Graphite carbon nanofibers; GO: Graphene oxide; GOCQ: Graphene oxide-chloroquine; GONPs: GO nanoplatelets; HCT 116 cells: Human colon cancer cells; HE: Hematoxylin and eosin; HepG2 cells: Human hepatoma cells; HIF-1: Hypoxia-inducible factor 1; HL-60 cells: Human promyelocytic leukemia cells; HUVECs: Human umbilical vein endothelial cells; IF: Intermediate fibers; IL-6: Interleukin-6; IONPs: Iron oxide NPs; JNK: c-Ju Au NPs inal kinase; LC3: Microtubule-associated protein light chain 3; LMP: Lysosomal membrane permeabilization; LTP: Long-term potentiation; MCF7 cells: Human breast ccancer cells; MF: Microfilaments; MFeNPs: Magnetic iron oxide NPs; miRNAs: MicroRNAs; MMP: Mitochondrial membrane potential; MSNs: Mesoporous silica NMs; MT: Microtubules; mtDNA: Mitochondrial DNA; MTOR: Mammalian target of rapamycin; mtROS: Mitochondrial reactive oxygen species; NAC: N-acetyl L-cysteine; $\mathrm{NH}_{2}$-PS: $\mathrm{NH}_{2}$-labeled polystyrene; NMs: Nanomaterials; NPs: Nanoparticles; OA: Osteoarthritis; oMWCNTs: Oxidized multiwalled carbon nanotubes; PAMA M: Polyamidoamine dendrimers; PC12 cells: Rat pheochromocytoma cells; PD: Parkinson's disease; PDT: Photodynamic therapy; PE: Phosphatidyl ethanolamine; PEG: polyethylene glycol; PEl: Polyethylenimine; PLGA: Poly lactic-co-glycolic acid; PTR: Pleurotus tuber-regium; PU NPs: polyurethane NPs; RA: Rheumatoid arthritis; RCD: Regulated cell death; RES: Reticuloendothelial system; RIP: Receptor interaction protein; ROS: Reactive oxygen species; Se-Cur NPs: Curcumin-loaded selenium NPs; SeNPs: Selenium NPs; SiNPs: Silica NPs; SLE: Systemic lupus erythematosus; SPIONs: Superparamagnetic iron oxide NPs; SWCNTs: Single-walled carbon nanotube; $\mathrm{TiO}_{2}$ : Titanium dioxide; TLR-4: Toll-like receptor-4; TNF a: Tumor necrosis factor-a; UCNs: Upconversion NPS; UPR: Unfolded protein response; VEGFR2: Vascular endothelial growth factor receptor 2; VSMCs: Vascular smooth muscle cells; ZnO: Zinc oxide; 3-MA: 3-methyladenine; 2-ME: 2 methoxyestradiol

\section{Acknowledgments}

Not applicable.

\section{Authors' contributions}

All authors contributed to the design and concept of this article. Zhang Yaqing and Feng Xiaoli drafted the manuscript. Feng Xiaoli critically revised the manuscript. All authors read and approved the final manuscript.

\section{Funding}

This work was supported by the National Key Research and Development Program of China (2016YFC1 102603 and 2016YFC1102605), the National Natural Science Foundation of China (51672122, 81870786 and 81701026) and Medical Scientific Research Foundation of Guangdong Province of China (A2017539).

\section{Availability of data and materials}

Databases/repositories and materials is not applicable in this review.

\section{Ethics approval and consent to participate}

Not applicable.

\section{Consent for publication}

Not applicable.

\section{Competing interests}

The authors declare that they have no competing interests.

\section{Author details}

${ }^{1}$ Stomatological Hospital, Southern Medical University, 366 South Jiangnan Road, Guangzhou 510280, China. ${ }^{2}$ Nanfang Hospital, Southern Medical University, 1838 North Guangzhou Street, Guangzhou 510515, China. ${ }^{3}$ Orthodontic Department, Stomatological Hospital, Southern Medical University, 366 South Jiangnan Road, Guangzhou 510280, China.
Received: 30 July 2019 Accepted: 28 July 2020

Published online: 16 October 2020

\section{References}

1. Bleeker EA, de Jong WH, Geertsma RE, Groenewold M, Heugens EH, KoersJacquemijns $\mathrm{M}$, et al. Considerations on the EU definition of a nanomaterial: science to support policy making. Regul Toxicol Pharmacol. 2013;65(1):119-25.

2. Ma X, Xiong Y, Lee LTO. Application of Nanoparticles for Targeting G Protein-Coupled Receptors. Int J Mol Sci. 2018;19(7):2006.

3. Chang L, Wu H, He X, Chen L, Zhang Y. A highly sensitive fluorescent turnon biosensor for glycoproteins based on boronic acid functional polymer capped Mn-doped ZnS quantum dots. Anal Chim Acta. 2017;995:91-8.

4. Li H, Chen Q, Zhao J, Urmila K. Fabricating upconversion fluorescent nanoparticles modified substrate for dynamical control of cancer cells and pathogenic bacteria. J Biophotonics. 2017;10(8):1034-42

5. Wang F, Xu Y, LV C, Han C, Li Y. Enhanced wound healing activity of PEG/ $\mathrm{PCL}$ copolymer combined with bioactive nanoparticles in wound care after anorectal surgery: Via bio-inspired methodology. J Photochem Photobiol B. 2018;187:54-60.

6. Chu J, Shi P, Yan W, Fu J, Yang Z, He C, et al. PEGylated graphene oxidemediated quercetin-modified collagen hybrid scaffold for enhancement of MSCs differentiation potential and diabetic wound healing. Nanoscale. 2018; 10(20):9547-60.

7. Zhang Y, Zhang C, Liu K, Zhu X, Liu F, Ge X. Biologically synthesized titanium oxide nanostructures combined with morphogenetic protein as wound healing agent in the femoral fracture after surgery. J Photochem Photobiol B. 2018;182:35-41.

8. Jiang H, Liu Y, Luo W, Wang $Y$, Tang $X$, Dou W, et al. A resumable twophoton fluorescent probe for $\mathrm{Cu}\left({ }^{2+}\right)$ and $\mathrm{S}^{\left({ }^{2}\right)}$ ) based on magnetic silica core-shell $\mathrm{Fe}_{3} \mathrm{O}_{4} @ \mathrm{SiO}_{2}$ nanoparticles and its application in bioimaging. Anal Chim Acta. 2018;1014:91-9.

9. Liu JM, Zhang DD, Fang GZ, Wang S. Erythrocyte membrane bioinspired near-infrared persistent luminescence nanocarriers for in vivo longcirculating bioimaging and drug delivery. Biomaterials. 2018;165:39-47.

10. Guo C, Robertson S, Weber RJM, Buckley A, Warren J, Hodgson A, et al. Pulmonary toxicity of inhaled nano-sized cerium oxide aerosols in SpragueDawley rats. Nanotoxicology. 2019;13(6):733-50.

11. Jalink K, Cheng SSY, Ben Ireland S, Louise Meunier MAF. Silver nanoparticle uptake in the human lung assessed through in-vitro and in-silico methods. Environ Pollut. 2020;259:113880.

12. Chen Z, Han S, Zhou D, Zhou S, Jia G. Effects of oral exposure to titanium dioxide nanoparticles on gut microbiota and gut-associated metabolism in vivo. Nanoscale. 2019;11(46):22398-412.

13. Mei L, Zhang X, Yin W, Dong X, Guo Z, Fu W, et al. Translocation, biotransformation-related degradation, and toxicity assessment of polyvinylpyrrolidone-modified 2H-phase nano-MoS2. Nanoscale. 2019;11(11): 4767-80.

14. Zhang J, Wang B, Wang $H, H e ~ H$, Wu Q, Qin X, et al. Disruption of the superoxide anions-mitophagy regulation axis mediates copper oxide nanoparticles-induced vascular endothelial cell death. Free Radic Biol Med. 2018;129:268-78.

15. Mostovenko E, Young T, Muldoon PP, Bishop L, Canal CG, Vucetic A, et al. Nanoparticle exposure driven circulating bioactive peptidome causes systemic inflammation and vascular dysfunction. Part Fibre Toxicol. 2019; 16(1):20.

16. Gallo A, Manfra L, Boni R, Rotini A, Migliore L, Tosti E. Cytotoxicity and genotoxicity of $\mathrm{CuO}$ nanoparticles in sea urchin spermatozoa through oxidative stress. Environ Int. 2018;118:325-33.

17. Evans SJ, Clift MJD, Singh N, Wills JW, Hondow N, Wilkinson TS, et al. In vitro detection of in vitro secondary mechanisms of genotoxicity induced by engineered nanomaterials. Part Fibre Toxicol. 2019;16(1):8.

18. Manna K, Mishra S, Saha M, Mahapatra S, Saha C, Yenge G, et al. Amelioration of diabetic nephropathy using pomegranate peel extractstabilized gold nanoparticles: assessment of NF-KB and Nrf2 signaling system. Int J Nanomedicine. 2019;14:1753-77.

19. Zhang L, Wang X, Miao Y, Chen Z, Qiang P, Cui L, et al. Magnetic ferroferric oxide nanoparticles induce vascular endothelial cell dysfunction and inflammation by disturbing autophagy. J Hazard Mater. 2016;304:186-95.

20. Roy R, Singh SK, Chauhan LK, Das M, Tripathi A, Dwivedi PD. Zinc oxide nanoparticles induce apoptosis by enhancement of autophagy via PI3K/Akt/ mTOR inhibition. Toxicol Lett. 2014;227(1):29-40. 
21. Klionsky DJ. Autophagy: from phenomenology to molecular understanding in less than a decade. Nat Rev Mol Cell Biol. 2007;8(11):931-7.

22. Kimura S, Fujita N, Noda T, Yoshimori T. Monitoring autophagy in mammalian cultured cells through the dynamics of LC3. Methods Enzymol. 2009:452:1-12

23. Andón FT, Fadeel B. Programmed cell death: molecular mechanisms and implications for safety assessment of nanomaterials. Acc Chem Res. 2013; 46(3):733-42.

24. Johnson-Lyles DN, Peifley K, Lockett S, Neun BW, Hansen M, Clogston J, et al. Fullerenol cytotoxicity in kidney cells is associated with cytoskeleton disruption, autophagic vacuole accumulation, and mitochondrial dysfunction. Toxicol Appl Pharmacol. 2010;248(3):249-58.

25. Wang J, Yu Y, Lu K, Yang M, Li Y, Zhou X, et al. Silica nanoparticles induce autophagy dysfunction via lysosomal impairment and inhibition of autophagosome degradation in hepatocytes. Int J Nanomedicine. 2017;12: 809-25

26. Chiu HW, Xia T, Lee YH, Chen CW, Tsai JC, Wang YJ. Cationic polystyrene nanospheres induce autophagic cell death through the induction of endoplasmic reticulum stress. Nanoscale. 2015;7(2):736-46.

27. Hussain S, Al-Nsour F, Rice AB, Marshburn J, Yingling B, Ji Z, et al. Cerium dioxide nanoparticles induce apoptosis and autophagy in human peripheral blood monocytes. ACS Nano. 2012;6(7):5820-58299.

28. Stern ST, Adiseshaiah PP, Crist RM. Autophagy and lysosomal dysfunction as emerging mechanisms of nanomaterial toxicity. Part Fibre Toxicol. 2012;9:20.

29. Guo C, Yang M, Jing L, Wang J, Yu Y, Li Y, et al. Amorphous silica nanoparticles trigger vascular endothelial cell injury through apoptosis and autophagy via reactive oxygen species-mediated MAPK/BCl-2 and PI3K/Akt/ mTOR signaling. Int J Nanomedicine. 2016;11:5257-76.

30. Shen J, Yang D, Zhou X, Wang Y, Tang S, Yin H, et al. Role of Autophagy in Zinc Oxide Nanoparticles-Induced Apoptosis of Mouse LEYDIG Cells. Int J Mol Sci. 2019;20(16):4042

31. Feng $X$, Chen L, Guo W, Zhang Y, Lai $X$, Shao L, et al. Graphene oxide induces p62/SQSTM-dependent apoptosis through the impairment of autophagic flux and lysosomal dysfunction in PC12 cells. Acta Biomater. 2018;81:278-92.

32. Kim JY, Paton JC, Briles DE, Rhee DK, Pyo S. Streptococcus pneumoniae induces pyroptosis through the regulation of autophagy in murine microglia. Oncotarget. 2015;6(42):44161-78.

33. Arya BD, Mittal S, Joshi P, Pandey AK, Ramirez-Vick JE, Singh SP. Graphene oxide-chloroquine nanoconjugate induce necroptotic death in A549 cancer cells through autophagy modulation. Nanomedicine (London). 2018;13(18): 2261-82.

34. Hou W, Xie Y, Song X, Sun X, Lotze MT, Zeh HJ, et al. Autophagy promotes ferroptosis by degradation of ferritin. Autophagy. 2016;12(8):1425-8.

35. Jiang $Y$, Yang $N$, Zhang $H$, Sun $B$, Hou $C$, Ji C, et al. Enhanced in vivo antitumor efficacy of dual-functional peptide-modified docetaxel nanoparticles through tumor targeting and Hsp90 inhibition. J Control Release. 2016;221:26-36.

36. Lan AP, Chen J, Zhao Y, Chai Z, Hu Y. mTOR Signaling in Parkinson's Disease. NeuroMolecular Med. 2017;19(1):1-10

37. Bianco A, Muller S. Nanomaterials, Autophagy, and Lupus Disease. ChemMedChem. 2016;11(2):166-74

38. Han XB, Li HX, Jiang YQ, Wang H, Li XS, Kou JY, et al. Upconversion nanoparticle-mediated photodynamic therapy induces autophagy and cholesterol efflux of macrophage-derived foam cells via ROS generation. Cell Death Dis. 2017;8(6):e2864

39. Zhu M, Nie G, Meng H, Xia T, Nel A, Zhao Y. Physicochemical properties determine nanomaterial cellular uptake, transport, and fate. Acc Chem Res. 2013;46(3):622-31

40. Shadjou N, Hasanzadeh M. Bone tissue engineering using silica-based mesoporous nanobiomaterials: Recent progress. Mater Sci Eng C Mater Biol Appl. 2015:55:401-9.

41. Iturrioz-Rodríguez N, Correa-Duarte MA, Fanarraga ML. Controlled drug delivery systems for cancer based on mesoporous silica nanoparticles. Int Nanomedicine. 2019;14:3389-401

42. Zheng G, Zhao R, Xu A, Shen Z, Chen X, Shao J. Co-delivery of sorafenib and siVEGF based on mesoporous silica nanoparticles for ASGPR mediated targeted HCC therapy. Eur J Pharm Sci. 2018;111:492-502.

43. Hartono SB, Yu M, Gu W, Yang J, Strounina E, Wang X, et al. Synthesis of multi-functional large pore mesoporous silica nanoparticles as gene carriers. Nanotechnology. 2014;25(5):055701.
44. Choi Y, Lee JE, Lee JH, Jeong JH, Kim J. A Biodegradation Study of SBA-15 Microparticles in Simulated Body Fluid and in Vivo. Langmuir. 2015;31(23): 6457-62.

45. Huang X, Li L, Liu T, Hao N, Liu H, Chen D, et al. The shape effect of mesoporous silica nanoparticles on biodistribution, clearance, and biocompatibility in vivo. ACS Nano. 2011;5(7):5390-9.

46. Shan XH, Wang $P$, Xiong F, Lu HY, Hu H. Detection of human breast cancer cells using a 2-deoxy-D-glucose-functionalized superparamagnetic iron oxide nanoparticles. Cancer Biomark. 2017;18(4):367-74.

47. Zou J, Ostrovsky S, Israel LL, Feng H, Kettunen MI, Lellouche JM, et al. Efficient penetration of ceric ammonium nitrate oxidant-stabilized gammamaghemite nanoparticles through the oval and round windows into the rat inner ear as demonstrated by MRI. J Biomed Mater Res B Appl Biomater. 2017;105(7):1883-91.

48. Rego GNA, Mamani JB, Souza TKF, Nucci MP, Silva HRD, Gamarra LF. Therapeutic evaluation of magnetic hyperthermia using $\mathrm{Fe}_{3} \mathrm{O}_{4}$-aminosilanecoated iron oxide nanoparticles in glioblastoma animal model. Einstein (Sao Paulo). 2019;17(4):eAO4786.

49. Boroun S, Larachi F. Tuning mass transport in magnetic nanoparticle-filled viscoelastic hydrogels using low-frequency rotating magnetic fields. Soft Matter. 2017;13(36):6259-69.

50. Soares PI, Lochte F, Echeverria C, Pereira LC, Coutinho JT, Ferreira IM, et al. Thermal and magnetic properties of iron oxide colloids: influence of surfactants. Nanotechnology. 2015;26(42):425704.

51. Alia SM, Duong K, Liu T, Jensen K, Yan Y. Palladium and gold nanotubes as oxygen reduction reaction and alcohol oxidation reaction catalysts in base. ChemSusChem. 2014;7(6):1739-44.

52. Raveendran S, Lim HT, Maekawa T, Vadakke Matham M, Sakthi Kumar D. Gold nanocages entering into the realm of high-contrast photoacoustic ocular imaging. Nanoscale. 2018;10(29):13959-68.

53. You J, Zhang G, Li C. Exceptionally high payload of doxorubicin in hollow gold nanospheres for near-infrared light-triggered drug release. ACS Nano. 2010;4(2):1033-41

54. Ratto F, Matteini P, Centi S, Rossi F, Pini R. Gold nanorods as new nanochromophores for photothermal therapies. J Biophotonics. 2011;4(1-2): 64-73.

55. Zhang W, Ji Y, Meng J, Wu X, Xu H. Probing the behaviors of gold nanorods in metastatic breast cancer cells based on UV-vis-NIR absorption spectroscopy. PLoS One. 2012;7(2):e31957.

56. Ortiz N, Zoellner B, Hong SJ, Ji Y, Wang T, Liu Y, et al. Harnessing Hot Electrons from Near IR Light for Hydrogen Production Using Pt-EndCapped-AuNRs. ACS Appl Mater Interfaces. 2017;9(31):25962-9.

57. Haine AT, Niidome T. Gold Nanorods as Nanodevices for Bioimaging, Photothermal Therapeutics, and Drug Delivery. Chem Pharm Bull (Tokyo). 2017;65(7):625-8.

58. Ma N, Wu FG, Zhang X, Jiang YW, Jia HR, Wang HY, et al. Shape-Dependent Radiosensitization Effect of Gold Nanostructures in Cancer Radiotherapy: Comparison of Gold Nanoparticles, Nanospikes, and Nanorods. ACS Appl Mater Interfaces. 2017;9(15):13037-48.

59. Nazar MF, Myakonkaya O, Shah SS, Eastoe J. Separating nanoparticles from microemulsions. J Colloid Interface Sci. 2011;354(2):624-9.

60. Nakamura S, Sato M, Sato Y, Ando N, Takayama T, Fujita M, et al. Synthesis and Application of Silver Nanoparticles (Ag NPs) for the Prevention of Infection in Healthcare Workers. Int J Mol Sci. 2019;20(15):3620.

61. Lebedová J, Hedberg YS, Odnevall Wallinder I, Karlsson HL. Size-dependent genotoxicity of silver, gold and platinum nanoparticles studied using the mini-gel comet assay and micronucleus scoring with flow cytometry. Mutagenesis. 2018;33(1):77-85

62. Patlolla AK, Hackett D, Tchounwou PB. Genotoxicity study of silver nanoparticles in bone marrow cells of Sprague-Dawley rats. Food Chem Toxicol. 2015:85:52-60.

63. Lahri R, Rahman M, Wright M, Kosmas $P$, Thanou M. Zinc oxide nanoparticles as contrast-enhancing agents for microwave imaging. Med Phys. 2018.

64. Bhattacharyya P, Agarwal B, Goswami M, Maiti D, Baruah S, Tribedi P. Zinc oxide nanoparticle inhibits the biofilm formation of Streptococcus pneumoniae. Antonie Van Leeuwenhoek. 2018;111(1):89-99.

65. Gehrke T, Scherzad A, Ickrath P, Schendzielorz P, Hagen R, Kleinsasser N, et al. Zinc oxide nanoparticles antagonize the effect of Cetuximab on head and neck squamous cell carcinoma in vitro. Cancer Biol Ther. 2017;18(7): $513-8$. 
66. Azam A, Ahmed AS, Oves M, Khan MS, Habib SS, Memic A. Antimicrobia activity of metal oxide nanoparticles against Gram-positive and Gramnegative bacteria: a comparative study. Int J Nanomedicine. 2012;7:6003-9.

67. Su Y, Wu D, Xia H, Zhang C, Shi J, Wilkinson KJ, et al. Metallic nanoparticles induced antibiotic resistance genes attenuation of leachate culturable microbiota: The combined roles of growth inhibition, ion dissolution and oxidative stress. Environ Int. 2019;128:407-16.

68. Naqvi QU, Kanwal A, Qaseem S, Naeem M, Ali SR, Shaffique M, et al. Sizedependent inhibition of bacterial growth by chemically engineered spherical ZnO nanoparticles. J Biol Phys. 2019;45(2):147-59.

69. Zhang H, Wang Z, Li R, Guo J, Li Y, Zhu J, et al. $\mathrm{TiO}_{2}$ supported on reed straw biochar as an adsorptive and photocatalytic composite for the efficient degradation of sulfamethoxazole in aqueous matrices. Chemosphere. 2017;185:351-60.

70. Behnam MA, Emami F, Sobhani Z, Dehghanian AR. The application of titanium dioxide $\left(\mathrm{TiO}_{2}\right)$ nanoparticles in the photo-thermal therapy of melanoma cancer model. Iran J Basic Med Sci. 2018;21(11):1133-9.

71. Ion R, Necula MG, Mazare A, Mitran V, Neacsu P, Schmuki P, et al. Drug Delivery Systems Based on Titania Nanotubes and Active Agents for Enhanced Osseointegration of Bone Implants. Curr Med Chem. 2020;27(6): 854-902.

72. Liao C, Li Y, Tjong SC. Visible-Light Active Titanium Dioxide Nanomaterials with Bactericidal Properties. Nanomaterials (Basel). 2020;10(1):124.

73. Kumar M, Raza K. C60-fullerenes as Drug Delivery Carriers for Anticancer Agents: Promises and Hurdles. Pharm Nanotechnol. 2017;5(3):169-79.

74. Cuevas-Flores MDR, Garcia-Revilla MA, Bartolomei M. Noncovalent interactions between cisplatin and graphene prototypes. J Comput Chem. 2018;39(2):71-80.

75. Tsai HC, Lin JY, Maryani F, Huang CC, Imae T. Drug-loading capacity and nuclear targeting of multiwalled carbon nanotubes grafted with anionic amphiphilic copolymers. Int J Nanomedicine. 2013;8:4427-40.

76. Kim SH, Lee JE, Sharker SM, Jeong JH, In I, Park SY. In Vitro and In Vivo Tumor Targeted Photothermal Cancer Therapy Using Functionalized Graphene Nanoparticles. Biomacromolecules. 2015;16(11):3519-29.

77. Liang X, Shang W, Chi C, Zeng C, Wang K, Fang C, et al. Dye-conjugated single-walled carbon nanotubes induce photothermal therapy under the guidance of near-infrared imaging. Cancer Lett. 2016;383(2):243-9.

78. Kang Y, Liu J, Yin S, Jiang Y, Feng X, Wu J, et al. Oxidation of Reduced Graphene Oxide via Cellular Redox Signaling Modulates Actin-Mediated Neurotransmission. ACS Nano. 2020;14(3):3059-74.

79. Johnson BM, Fraietta JA, Gracias DT, Hope JL, Stairiker CJ, Patel PR, et al. Acute exposure to $\mathrm{ZnO}$ nanoparticles induces autophagic immune cell death. Nanotoxicology. 2015;9(6):737-48.

80. Yu KN, Sung JH, Lee S, Kim JE, Kim S, Cho WY, et al. Inhalation of titanium dioxide induces endoplasmic reticulum stress-mediated autophagy and inflammation in mice. Food Chem Toxicol. 2015;85:106-13.

81. He Z, Hu Y, Nie T, Tang H, Zhu J, Chen K, et al. Size-controlled lipid nanoparticle production using turbulent mixing to enhance oral DNA delivery. Acta Biomater. 2018;81:195-207.

82. Fan J, Sun Y, Wang S, Li Y, Zeng X, Cao Z, et al. Inhibition of autophagy overcomes the nanotoxicity elicited by cadmium-based quantum dots. Biomaterials. 2016;78:102-14.

83. Mao BH, Chen ZY, Wang YJ, Yan SJ. Silver nanoparticles have lethal and sublethal adverse effects on development and longevity by inducing ROSmediated stress responses. Sci Rep. 2018:8(1):2445.

84. Sadhukha T, Wiedmann TS, Panyam J. Enhancing therapeutic efficacy through designed aggregation of nanoparticles. Biomaterials. 2014;35(27): 7860-9.

85. Lin YF, Chiu IJ, Cheng FY, Lee YH, Wang YJ, Hsu YH, et al. The role of hypoxia-inducible factor-1a in zinc oxide nanoparticle-induced nephrotoxicity in vitro and in vivo. Part Fibre Toxicol. 2016;13(1):52.

86. Pati R, Das I, Mehta RK, Sahu R, Sonawane A. Zinc-Oxide Nanoparticles Exhibit Genotoxic, Clastogenic, Cytotoxic and Actin Depolymerization Effects by Inducing Oxidative Stress Responses in Macrophages and Adult Mice. Toxicol Sci. 2016;150(2):454-72.

87. Luyts K, Van Den Broucke S, Hemmeryckx B, Poels K, Scheers H, Casas L, et al. Nanoparticles in the lungs of old mice: Pulmonary inflammation and oxidative stress without procoagulant effects. Sci Total Environ. 2018;644 907-15.
88. Yang K, Gong H, Shi X, Wan J, Zhang Y, Liu Z. In vivo biodistribution and toxicology of functionalized nano-graphene oxide in mice after oral and intraperitoneal administration. Biomaterials. 2013;34(11):2787-95.

89. Waegeneers N, Brasseur A, Van Doren E, Van der Heyden S, Serreyn PJ, Pussemier $L$, et al. Short-term biodistribution and clearance of intravenously administered silica nanoparticles. Toxicol Rep. 2018;5:632-8.

90. Fu C, Liu T, Li L, Liu H, Chen D, Tang F. The absorption, distribution, excretion and toxicity of mesoporous silica nanoparticles in mice following different exposure routes. Biomaterials. 2013;34(10):2565-75.

91. Wei Q, Zhan L, Juanjuan B, Jing W, Jianjun W, Taoli S, et al. Biodistribution of co-exposure to multi-walled carbon nanotubes and nanodiamonds in mice. Nanoscale Res Lett. 2012;7(1):473.

92. Ueno T, Komatsu M. Autophagy in the liver: functions in health and disease. Nat Rev Gastroenterol Hepatol. 2017;14(3):170-84.

93. Yao Y, Zang Y, Qu J, Tang M, Zhang T. The Toxicity Of Metallic Nanoparticles On Liver: The Subcellular Damages, Mechanisms, And Outcomes. Int J Nanomedicine. 2019;14:8787-804.

94. Chao X, Wang H, Jaeschke $H$, Ding WX. Role and mechanisms of autophagy in acetaminophen-induced liver injury. Liver Int. 2018;38(8):1363-74.

95. Tian Z, Wang M, Yao N, Yang S, Liu J, Yang Y, et al. Expression of autophagy-modulating genes in peripheral blood mononuclear cells from familial clustering patients with chronic hepatitis B virus infection. Arch Virol. 2019;164(8):2005-13.

96. Akkoç Y, Gözüaçık D. Autophagy and liver cancer. Turk J Gastroenterol. 2018;29(3):270-82.

97. Lee TY, Liu MS, Huang LJ, Lue SI, Lin LC, Kwan AL, et al. Bioenergetic failure correlates with autophagy and apoptosis in rat liver following silver nanoparticle intraperitoneal administration. Part Fibre Toxicol. 2013;10:40.

98. Zhu S, Zhang J, Zhang L, Ma W, Man N, Liu Y, et al. Inhibition of Kupffer Cell Autophagy Abrogates Nanoparticle-Induced Liver Injury. Adv Healthc Mater. 2017;6(9):1601252

99. Li Y, Zeng X, Wang S, Sun Y, Wang Z, Fan J, et al. Inhibition of autophagy protects against PAMAM dendrimers-induced hepatotoxicity. Nanotoxicology. 2015;9(3):344-55.

100. Yu Y, Duan J, Yu Y, Li Y, Zou Y, Yang Y, et al. Autophagy and autophagy dysfunction contribute to apoptosis in HepG2 cells exposed to nanosilica. Toxicol Res (Camb). 2016;5(3):871-82.

101. Horváth T, Papp A, Kiricsi M, Igaz N, Trenka V, Kozma G, et al. Investigation of the effect of titanium dioxide nanorods on the lungs in a subacute rat model. Orv Hetil. 2019;160(2):57-66.

102. Jiang X, Tang Q, Zhang J, Wang H, Bai L, Meng P, et al. Autophagydependent release of zinc ions is critical for acute lung injury triggered by zinc oxide nanoparticles. Nanotoxicology. 2018;12(9):1068-91.

103. Park EJ, Lee $\mathrm{GH}$, Han BS, Lee BS, Lee $\mathrm{S}$, Cho MH, et al. Toxic response of graphene nanoplatelets in vivo and in vitro. Arch Toxicol. 2015;89(9):155768.

104. Li C, Liu H, Sun Y, Wang H, Guo F, Rao S, et al. PAMAM nanoparticles promote acute lung injury by inducing autophagic cell death through the Akt-TSC2-mTOR signaling pathway. J Mol Cell Biol. 2009;1(1):37-45.

105. Liu HL, Zhang YL, Yang N, Zhang YX, Liu XQ, Li CG, et al. A functionalized single-walled carbon nanotube-induced autophagic cell death in human lung cells through Akt-TSC2-mTOR signaling. Cell Death Dis. 2011;2(5):e159.

106. Yu KN, Kim JE, Seo HW, Chae C, Cho MH. Differential toxic responses between pristine and functionalized multiwall nanotubes involve induction of autophagy accumulation in murine lung. J Toxicol Environ Health A. 2013;76(23):1282-92.

107. Hamilton RF, Wu Z, Mitra S, Holian A. The Effects of Varying Degree of MWCNT Carboxylation on Bioactivity in Various In Vivo and In Vitro Exposure Models. Int J Mol Sci. 2018;19(2):354

108. Zhang L, Cheng S, Jiang X, Zhang J, Meng P, Tang Q, et al. Pregnancy exposure to carbon black nanoparticles exacerbates bleomycin-induced lung fibrosis in offspring via disrupting LKB1-AMPK-ULK1 axis-mediated autophagy. Toxicology. 2019;425:152244.

109. Chen X, Zhouhua W, Jie Z, Xinlu F, Jinqiang L, Yuwen Q, et al. Renal interstitial fibrosis induced by high-dose mesoporous silica nanoparticles via the NF-KB signaling pathway. Int J Nanomedicine. 2015;10:1-22.

110. Nemmar A, Al-Salam S, Al Ansari Z, Alkharas ZA, Al Ahbabi RM, Beegam S, et al. Impact of Pulmonary Exposure to Cerium Oxide Nanoparticles on Experimental Acute Kidney Injury. Cell Physiol Biochem. 2019;52(3):439-54. 
111. Jiang $S$, Lin $Y$, Yao $H$, Yang C, Zhang L, Luo B, et al. The role of unfolded protein response and ER-phagy in quantum dots-induced nephrotoxicity: an in vitro and in vivo study. Arch Toxicol. 2018;92(4):1421-34.

112. Zhang $X$, Zhang $H$, Liang $X$, Zhang J, Tao W, Zhu $X$, et al. Iron Oxide Nanoparticles Induce Autophagosome Accumulation through Multiple Mechanisms: Lysosome Impairment, Mitochondrial Damage, and ER Stress. Mol Pharm. 2016;13(7):2578-87.

113. Komatsu M, Waguri S, Chiba T, Murata S, Iwata J, Tanida I, et al. Loss of autophagy in the central nervous system causes neurodegeneration in mice. Nature. 2006;441(7095):880-4.

114. Pellacani C, Costa LG. Role of autophagy in environmental neurotoxicity. Environ Pollut. 2018;235:791-805.

115. Chen L, Zhang B, Toborek M. Autophagy is involved in nanoaluminainduced cerebrovascular toxicity. Nanomedicine. 2013;9(2):212-21.

116. Gao J, Zhang X, Yu M, Ren G, Yang Z. Cognitive deficits induced by multiwalled carbon nanotubes via the autophagic pathway. Toxicology. 2015;337: 21-9.

117. Hawkins SJ, Crompton LA, Sood A, Saunders M, Boyle NT, Buckley A, et al. Nanoparticle-induced neuronal toxicity across placental barriers is mediated by autophagy and dependent on astrocytes. Nat Nanotechnol. 2018;13(5): 427-33.

118. Rossi S, Savi M, Mazzola M, Pinelli S, Alinovi R, Gennaccaro L, et al. Subchronic exposure to titanium dioxide nanoparticles modifies cardiac structure and performance in spontaneously hypertensive rats. Part Fibre Toxicol. 2019;16(1):25.

119. Carll AP, Salatini R, Pirela SV, Wang Y, Xie Z, Lorkiewicz P, et al. Inhalation of printer-emitted particles impairs cardiac conduction, hemodynamics, and autonomic regulation and induces arrhythmia and electrical remodeling in rats. Part Fibre Toxicol. 2020;17(1):7.

120. Zhang Q, Liu Z, Du J, Qin W, Lu M, Cui H, et al. Dermal exposure to nano$\mathrm{TiO}_{2}$ induced cardiovascular toxicity through oxidative stress, inflammation and apoptosis. J Toxicol Sci. 2019;44(1):35-45.

121. Chen Z, Meng H, Xing G, Yuan H, Zhao F, Liu R, et al. Age-related differences in pulmonary and cardiovascular responses to $\mathrm{SiO}_{2}$ nanoparticle inhalation: nanotoxicity has susceptible population. Environ Sci Technol. 2008;42(23):8985-92.

122. Chen R, Zhang L, Ge C, Tseng MT, Bai R, Qu Y, et al. Subchronic toxicity and cardiovascular responses in spontaneously hypertensive rats after exposure to multiwalled carbon nanotubes by intratracheal instillation. Chem Res Toxicol. 2015;28(3):440-50.

123. Kang GS, Gillespie PA, Gunnison A, Moreira AL, Tchou-Wong KM, Chen LC. Long-term inhalation exposure to nickel nanoparticles exacerbated atherosclerosis in a susceptible mouse model. Environ Health Perspect. 2011;119(2):176-81.

124. Khosravi Y, Salimi A, Pourahmad J, Naserzadeh P, Seydi E. Inhalation exposure of nano diamond induced oxidative stress in lung, heart and brain. Xenobiotica. 2018:48(8):860-6.

125. Du Z, Chen S, Cui G, Yang Y, Zhang E, Wang Q, et al. Silica nanoparticles induce cardiomyocyte apoptosis via the mitochondrial pathway in rats following intratracheal instillation. Int J Mol Med. 2019;43(3):1229-40.

126. Duan J, Yu Y, Yu Y, Li Y, Huang P, Zhou X, et al. Silica nanoparticles enhance autophagic activity, disturb endothelial cell homeostasis and impair angiogenesis. Part Fibre Toxicol. 2014;11:50.

127. You R, Ho YS, Hung CH, Liu Y, Huang CX, Chan HN, et al. Silica nanoparticles induce neurodegeneration-like changes in behavior, neuropathology, and affect synapse through MAPK activation. Part Fibre Toxicol. 2018;15(1):28.

128. Meldrum K, Robertson SB, Römer I, Marczylo T, Dean LSN, Rogers A, et al. Cerium dioxide nanoparticles exacerbate house dust mite induced type ॥ airway inflammation. Part Fibre Toxicol. 2018;15(1):24.

129. Win-Shwe $T$, Sone $H$, Kurokawa $Y$, Zeng $Y$, Zeng Q, Nitta $H$, et al. Effects of PAMAM dendrimers in the mouse brain after a single intranasal instillation. Toxicol Lett. 2014;228(3):207-15.

130. Liang $H$, Chen A, Lai $X$, Liu J, Wu J, Kang Y, et al. Neuroinflammation is induced by tongue-instilled $\mathrm{ZnO}$ nanoparticles via the $\mathrm{Ca}\left({ }^{2+}\right)$-dependent NF-KB and MAPK pathways. Part Fibre Toxicol. 2018;15(1):39.

131. Tabei Y, Fukui H, Nishioka A, Hagiwara Y, Sato K, Yoneda T, et al. Effect of iron overload from multi walled carbon nanotubes on neutrophil-like differentiated HL-60 cells. Sci Rep. 2019;9(1):2224.

132. Hillaireau H, Couvreur P. Nanocarriers' entry into the cell: relevance to drug delivery. Cell Mol Life Sci. 2009;66(17):2873-96.
133. Park EJ, Choi DH, Kim Y, Lee EW, Song J, Cho MH, et al. Magnetic iron oxide nanoparticles induce autophagy preceding apoptosis through mitochondrial damage and ER stress in RAW264.7 cells. Toxicol in Vitro. 2014;28(8):1402-12.

134. Zhu L, Guo D, Sun L, Huang Z, Zhang X, Ma W, et al. Activation of autophagy by elevated reactive oxygen species rather than released silver ions promotes cytotoxicity of polyvinylpyrrolidone-coated silver nanoparticles in hematopoietic cells. Nanoscale. 2017;9(17):5489-98,

135. González-Rodríguez A, Mayoral R, Agra N, Valdecantos MP, Pardo V, Miquilena-Colina ME, et al. Impaired autophagic flux is associated with increased endoplasmic reticulum stress during the development of NAFLD. Cell Death Dis. 2014;5(4):e1179.

136. Zeng XJ, Li P, Ning YL, Zhao Y, Peng Y, Yang N, et al. Impaired autophagic flux is associated with the severity of trauma and the role of $A(2 A) R$ in brain cells after traumatic brain injury. Cell Death Dis. 2018;9(2):252.

137. Yuan YG, Wang YH, Xing HH, Gurunathan S. Quercetin-mediated synthesis of graphene oxide-silver nanoparticle nanocomposites: a suitable alternative nanotherapy for neuroblastoma. Int J Nanomedicine. 2017;12:5819-39.

138. Orlando A, Cazzaniga E, Tringali M, Gullo F, Becchetti A, Minniti S, et al. Mesoporous silica nanoparticles trigger mitophagy in endothelial cells and perturb neuronal network activity in a size- and time-dependent manner. Int J Nanomedicine. 2017;12:3547-59.

139. Popp L, Tran V, Patel R, Segatori L. Autophagic response to cellular exposure to titanium dioxide nanoparticles. Acta Biomater. 2018;79:354-63.

140. Sohaebuddin SK, Thevenot PT, Baker D, Eaton JW, Tang L. Nanomaterial cytotoxicity is composition, size, and cell type dependent. Part Fibre Toxicol. 2010;7:22.

141. Xia T, Kovochich M, Liong M, Zink JI, Nel AE. Cationic polystyrene nanosphere toxicity depends on cell-specific endocytic and mitochondrial injury pathways. ACS Nano. 2008;2(1):85-96.

142. Ji X, Xu B, Yao M, Mao Z, Zhang Y, Xu G, et al. Graphene oxide quantum dots disrupt autophagic flux by inhibiting lysosome activity in GC-2 and TM4 cell lines. Toxicology. 2016;374:10-7.

143. Decan N, Wu D, Williams A, Bernatchez S, Johnston M, Hill M, et al. Characterization of in vitro genotoxic, cytotoxic and transcriptomic responses following exposures to amorphous silica of different sizes. Mutat Res Genet Toxicol Environ Mutagen. 2016;796:8-22.

144. Zhang J, Zou Z, Wang B, Xu G, Wu Q, Zhang Y, et al. Lysosomal deposition of copper oxide nanoparticles triggers HUVEC cells death. Biomaterials. 2018;161:228-39.

145. Cohignac V, Landry MJ, Ridoux A, Pinault M, Annangi B, Gerdil A, et al. Carbon nanotubes, but not spherical nanoparticles, block autophagy by a shape-related targeting of lysosomes in murine macrophages. Autophagy. 2018;14(8):1323-34.

146. Ma X, Wu Y, Jin S, Tian Y, Zhang X, Zhao Y, et al. Gold nanoparticles induce autophagosome accumulation through size-dependent nanoparticle uptake and lysosome impairment. ACS Nano. 2011;5(11):8629-39.

147. Lee WS, Yoo WH, Chae HJ. ER Stress and Autophagy. Curr Mol Med. 2015; 15(8):735-45.

148. Despres HW, Sabra A, Anderson P, Hemraz UD, Boluk Y, Sunasee R, et al. Mechanisms of the immune response cause by cationic and anionic surface functionalized cellulose nanocrystals using cell-based assays. Toxicol in Vitro. 2019:55:124-33.

149. Wei F, Wang Y, Luo Z, Li Y, Duan Y. New findings of silica nanoparticles induced ER autophagy in human colon cancer cell. Sci Rep. 2017;7:42591.

150. Lei $Y$, Wang C, Jiang Q, Sun X, Du Y, Zhu Y, et al. Calpain activation and disturbance of autophagy are induced in cortical neurons in vitro by exposure to $\mathrm{HA} / \beta_{-}-\mathrm{Ga}_{2} \mathrm{O}_{3}: \mathrm{Cr}\left({ }^{3+}\right)$ nanoparticles. PeerJ. 2018;6:e4365.

151. Mittal S, Sharma PK, Tiwari R, Rayavarapu RG, Shankar J, Chauhan LKS, et al. Impaired lysosomal activity mediated autophagic flux disruption by graphite carbon nanofibers induce apoptosis in human lung epithelial cells through oxidative stress and energetic impairment. Part Fibre Toxicol. 2017;14(1):15.

152. Liu J, Kang Y, Yin S, Chen A, Wu J, Liang H, et al. Key Role of Microtubule and Its Acetylation in a Zinc Oxide Nanoparticle-Mediated LysosomeAutophagy System. Small. 2019;15(25):e1901073.

153. Xu DQ, Wang Z, Wang CY, Zhang DY, Wan HD, Zhao ZL, et al. PAQR3 controls autophagy by integrating AMPK signaling to enhance ATG14Lassociated PI3K activity. EMBO J. 2016;35(5):496-514.

154. Huang G, Liu Z, He L, Luk KH, Cheung ST, Wong KH, et al. Autophagy is an important action mode for functionalized selenium nanoparticles to exhibit anti-colorectal cancer activity. Biomater Sci. 2018;6(9):2508-17. 
155. Eliopoulos AG, Havaki S, Gorgoulis VG. DNA Damage Response and Autophagy: A Meaningful Partnership. Front Genet. 2016;7:204.

156. Bae H, Guan JL. Suppression of autophagy by FIP200 deletion impairs DNA damage repair and increases cell death upon treatments with anticancer agents. Mol Cancer Res. 2011;9(9):1232-41.

157. Sadhu A, Ghosh I, Moriyasu Y, Mukherjee A, Bandyopadhyay M. Role of cerium oxide nanoparticle-induced autophagy as a safeguard to exogenous $\mathrm{H}_{2} \mathrm{O}_{2}$ mediated DNA damage in tobacco BY-2 cells. Mutagenesis. 2018;33(2):161-77.

158. Indo HP, Hawkins CL, Nakanishi I, Matsumoto Kl, Matsui H, Suenaga S, et al. Role of Mitochondrial Reactive Oxygen Species in the Activation of Cellular Signals, Molecules, and Function. Handb Exp Pharmacol. 2017;240:439-56.

159. Waiwijit U, Kandhavivorn W, Oonkhanond B, Lomas T, Phokaratkul D, Wisitsoraat A, et al. Cytotoxicity assessment of MDA-MB-231 breast cancer cells on screen-printed graphene-carbon paste substrate. Colloids Surf B: Biointerfaces. 2014;113:190-7.

160. Yu N, Li J, Singh PK, Ding D, Sun W, Tang Q, et al. The Superior Anticancer Effect of Reactive Oxygen Species-Responsive Paclitaxel Nanoparticles is Mediated Through Autophagic Cell Death. J Biomed Nanotechnol. 2019; 15(11):2251-61.

161. Yu Y, Duan J, Yu Y, Li Y, Liu X, Zhou X, et al. Silica nanoparticles induce autophagy and autophagic cell death in $\mathrm{HepG} 2$ cells triggered by reactive oxygen species. J Hazard Mater. 2014;270:176-86.

162. Zhao Y, Howe JL, Yu Z, Leong DT, Chu JJ, Loo JS, et al. Exposure to titanium dioxide nanoparticles induces autophagy in primary human keratinocytes. Small. 2013;9(3):387-92.

163. Zhang $X$, Yin H, Li Z, Zhang T, Yang Z. Nano-TiO ${ }_{2}$ induces autophagy to protect against cell death through antioxidative mechanism in podocytes. Cell Biol Toxicol. 2016:32(6):513-27.

164. Zhang JQ, Zhou W, Zhu SS, Lin J, Wei PF, Li FF, et al. Persistency of Enlarged Autolysosomes Underscores Nanoparticle-Induced Autophagy in Hepatocytes. Small. 2017;13(7):1602876.

165. Wu Q, Jin R, Feng T, Liu L, Yang L, Tao Y, et al. Iron oxide nanoparticles and induced autophagy in human monocytes. Int J Nanomedicine. 2017;12: 3993-4005.

166. Kumari M, Purohit MP, Patnaik S, Shukla Y, Kumar P, Gupta KC. Curcumin loaded selenium nanoparticles synergize the anticancer potential of doxorubicin contained in self-assembled, cell receptor targeted nanoparticles. Eur J Pharm Biopharm. 2018;130:185-99.

167. Xi C, Zhou J, Du S, Peng S. Autophagy upregulation promotes macrophages to escape mesoporous silica nanoparticle (MSN)-induced NF-KB-dependent inflammation. Inflamm Res. 2016;65(4):325-41.

168. Huang YJ, Hung KC, Hsieh FY, Hsu SH. Carboxyl-functionalized polyurethane nanoparticles with immunosuppressive properties as a new type of antiinflammatory platform. Nanoscale. 2015;7(48):20352-64.

169. Jin R, Liu L, Zhu W, Li D, Yang L, Duan J, et al. Iron oxide nanoparticles promote macrophage autophagy and inflammatory response through activation of toll-like Receptor-4 signaling. Biomaterials. 2019;203:23-30.

170. Chen RJ, Lee YH, Yeh YL, Wang YJ, Wang BJ. The Roles of Autophagy and the Inflammasome during Environmental Stress-Triggered Skin Inflammation. Int J Mol Sci. 2016;17(12).

171. Barman J, Kumar R, Saha G, Tiwari K, Dubey VK. Apoptosis: Mediator Molecules, Interplay with Other Cell Death Processes and Therapeutic Potentials. Curr Pharm Biotechnol. 2018;19(8):644-63.

172. Lim MH, Jeung IC, Jeong J, Yoon SJ, Lee SH, Park J, et al. Graphene oxide induces apoptotic cell death in endothelial cells by activating autophagy via calcium-dependent phosphorylation of c-Jun N-terminal kinases. Acta Biomater. 2016:46:191-203.

173. Wu W, Liu P, Li J. Necroptosis: an emerging form of programmed cell death. Crit Rev Oncol Hematol. 2012;82(3):249-58.

174. Horita H, Frankel AE, Thorburn A. Acute myeloid leukemia-targeted toxin activates both apoptotic and necroptotic death mechanisms. PLoS One. 2008:3(12):e3909.

175. Bonapace L, Bornhauser BC, Schmitz M, Cario G, Ziegler U, Niggli FK, et al. Induction of autophagy-dependent necroptosis is required for childhood acute lymphoblastic leukemia cells to overcome glucocorticoid resistance. J Clin Invest. 2010;120(4):1310-23.

176. Kanwal R, Gupta K, Gupta S. Cancer epigenetics: an introduction. Methods Mol Biol. 2015;1238:3-25.

177. Zou Z, Wu L, Ding H, Wang Y, Zhang Y, Chen X, et al. MicroRNA-30a sensitizes tumor cells to cis-platinum via suppressing beclin 1-mediated autophagy. J Biol Chem. 2012;287(6):4148-56.
178. Calin GA, Croce CM. MicroRNA signatures in human cancers. Nat Rev Cancer. 2006;6(11):857-66.

179. Assali A, Akhavan O, Mottaghitalab F, Adeli M, Dinarvand R, Razzazan S, et al. Cationic graphene oxide nanoplatform mediates miR-101 delivery to promote apoptosis by regulating autophagy and stress. Int J Nanomedicine. 2018;13:5865-86.

180. Gaur S, Wen Y, Song JH, Parikh NU, Mangala LS, Blessing AM, et al. Chitosan nanoparticle-mediated delivery of miRNA-34a decreases prostate tumor growth in the bone and its expression induces non-canonical autophagy. Oncotarget. 2015;6(30):29161-77.

181. Blanco J, Lafuente D, Gómez M, García T, Domingo JL, Sánchez DJ. Polyvinyl pyrrolidone-coated silver nanoparticles in a human lung cancer cells: timeand dose-dependent influence over p53 and caspase-3 protein expression and epigenetic effects. Arch Toxicol. 2017:91(2):651-66.

182. Öner D, Ghosh M, Bové H, Moisse M, Boeckx B, Duca RC, et al. Differences in MWCNT- and SWCNT-induced DNA methylation alterations in association with the nuclear deposition. Part Fibre Toxicol. 2018;15(1):11.

183. Galluzzi L, Pietrocola F, Bravo-San Pedro JM, Amaravadi RK, Baehrecke EH, Cecconi $F$, et al. Autophagy in malignant transformation and cancer progression. EMBO J. 2015;34(7):856-80.

184. Cho JH, Kim GY, Pan CJ, Anduaga J, Choi EJ, Mansfield BC, et al. Downregulation of SIRT1 signaling underlies hepatic autophagy impairment in glycogen storage disease type la. PLoS Genet. 2017;13(5):e1006819.

185. Jia C, Chen H, Zhang J, Zhou K, Zhuge Y, Niu C, et al. Role of pyroptosis in cardiovascular diseases. Int Immunopharmacol. 2019;67:311-8.

186. Liu L, Sha R, Yang L, Zhao X, Zhu Y, Gao J, et al. Impact of Morphology on Iron Oxide Nanoparticles-Induced Inflammasome Activation in Macrophages. ACS Appl Mater Interfaces. 2018;10(48):41197-206.

187. Jiang L, Greene MK, Insua JL, Pessoa JS, Small DM, Smyth P, et al. Clearance of intracellular Klebsiella pneumoniae infection using gentamicin-loaded nanoparticles. J Control Release. 2018;279:316-25.

188. Naji A, Muzembo BA, Yagyu K, Baba N, Deschaseaux F, Sensebé $L$, et al. Endocytosis of indium-tin-oxide nanoparticles by macrophages provokes pyroptosis requiring NLRP3-ASC-Caspase 1 axis that can be prevented by mesenchymal stem cells. Sci Rep. 2016;6:26162.

189. Zhang X, Luan J, Chen W, Fan J, Nan Y, Wang Y, et al. Mesoporous silica nanoparticles induced hepatotoxicity via NLRP3 inflammasome activation and caspase-1-dependent pyroptosis. Nanoscale. 2018;10(19):9141-52.

190. Lu Y, Xu S, Chen H, He M, Deng Y, Cao Z, et al. CdSe/ZnS quantum dots induce hepatocyte pyroptosis and liver inflammation via NLRP3 inflammasome activation. Biomaterials. 2016;90:27-39.

191. Li MY, Zhu XL, Zhao BX, Shi L, Wang W, Hu W, et al. Adrenomedullin alleviates the pyroptosis of Leydig cells by promoting autophagy via the ROS-AMPK-mTOR axis. Cell Death Dis. 2019;10(7):489.

192. Kong Y, Feng Z, Chen A, Qi Q, Han M, Wang S, et al. The Natural Flavonoid Galangin Elicits Apoptosis, Pyroptosis, and Autophagy in Glioblastoma. Front Oncol. 2019:9:942

193. Zhong Z, Umemura A, Sanchez-Lopez E, Liang S, Shalapour S, Wong J, et al. NF-kB Restricts Inflammasome Activation via Elimination of Damaged Mitochondria. Cell. 2016;164(5):896-910.

194. Duewell P, Kono H, Rayner KJ, Sirois CM, Vladimer G, Bauernfeind FG, et al, NLRP3 inflammasomes are required for atherogenesis and activated by cholesterol crystals. Nature. 2010;464(7293):1357-61.

195. Luo B, Li B, Wang W, Liu X, Xia Y, Zhang C, et al. NLRP3 gene silencing ameliorates diabetic cardiomyopathy in a type 2 diabetes rat model. PLoS One. 2014;9(8):e104771.

196. Katagiri N, Shobuike T, Chang B, Kukita A, Miyamoto H. The human apoptosis inhibitor NAIP induces pyroptosis in macrophages infected with Legionella pneumophila. Microbes Infect. 2012;14(13):1123-32.

197. Dixon SJ, Lemberg KM, Lamprecht MR, Skouta R, Zaitsev EM, Gleason CE, et al. Ferroptosis: an iron-dependent form of nonapoptotic cell death. Cell. 2012:149(5):1060-72.

198. Kim SE, Zhang L, Ma K, Riegman M, Chen F, Ingold I, et al. Ultrasmall nanoparticles induce ferroptosis in nutrient-deprived cancer cells and suppress tumour growth. Nat Nanotechnol. 2016;11(11):977-85.

199. Ou W, Mulik RS, Anwar A, McDonald JG, He X, Corbin IR. Low-density lipoprotein docosahexaenoic acid nanoparticles induce ferroptotic cell death in hepatocellular carcinoma. Free Radic Biol Med. 2017;112:597607.

200. Mailloux RJ, Harper ME. Mitochondrial proticity and ROS signaling: lessons from the uncoupling proteins. Trends Endocrinol Metab. 2012;23(9):451-8. 
201. Aguirre J, Lambeth JD. Nox enzymes from fungus to fly to fish and what they tell us about Nox function in mammals. Free Radic Biol Med. 2010; 49(9):1342-53.

202. Zhou Y, Hileman EO, Plunkett W, Keating MJ, Huang P. Free radical stress in chronic lymphocytic leukemia cells and its role in cellular sensitivity to ROSgenerating anticancer agents. Blood. 2003;101(10):4098-104.

203. Hileman EA, Achanta G, Huang P. Superoxide dismutase: an emerging target for cancer therapeutics. Expert Opin Ther Targets. 2001;5(6):697-710

204. Sun $K$, Guo XL, Zhao QD, Jing YY, Kou XR, Xie XQ, et al. Paradoxical role of autophagy in the dysplastic and tumor-forming stages of hepatocarcinoma development in rats. Cell Death Dis. 2013;4(2):e501.

205. Hanahan D, Weinberg RA. Hallmarks of cancer: the next generation. Cell. 2011;144(5):646-74.

206. Maes H, Rubio N, Garg AD, Agostinis P. Autophagy: shaping the tumor microenvironment and therapeutic response. Trends Mol Med. 2013;19(7): 428-46.

207. Cordani M, Somoza Á. Targeting autophagy using metallic nanoparticles: a promising strategy for cancer treatment. Cell Mol Life Sci. 2019;76(7):121542.

208. Sui X, Chen R, Wang Z, Huang Z, Kong N, Zhang M, et al. Autophagy and chemotherapy resistance: a promising therapeutic target for cancer treatment. Cell Death Dis. 2013;4(10):e838.

209. Vera-Ramirez L, Vodnala SK, Nini R, Hunter KW, Green JE. Autophagy promotes the survival of dormant breast cancer cells and metastatic tumour recurrence. Nat Commun. 2018:9(1):1944.

210. Cai-McRae X, Zhong H, Karantza V. Sequestosome 1/p62 facilitates HER2induced mammary tumorigenesis through multiple signaling pathways. Oncogene. 2015;34(23):2968-77.

211. Khan MI, Mohammad A, Patil G, Naqvi SA, Chauhan LK, Ahmad. Induction of ROS, mitochondrial damage and autophagy in lung epithelial cancer cells by iron oxide nanoparticles. Biomaterials. 2012;33(5):1477-88.

212. Li X, Feng J, Zhang R, Wang J, Su T, Tian Z, et al. Quaternized Chitosan/ Alginate- $\mathrm{Fe}_{3} \mathrm{O}_{4}$ Magnetic Nanoparticles Enhance the Chemosensitization of Multidrug-Resistant Gastric Carcinoma by Regulating Cell Autophagy Activity in Mice. J Biomed Nanotechnol. 2016;12(5):948-61.

213. Wang J, Gao S, Wang S, Xu Z, Wei L. Zinc oxide nanoparticles induce toxicity in CAL 27 oral cancer cell lines by activating PINK1/Parkin-mediated mitophagy. Int J Nanomedicine. 2018;13:3441-50.

214. Chen GY, Chen CL, Tuan HY, Yuan PX, Li KC, Yang HJ, et al. Graphene oxide triggers toll-like receptors/autophagy responses in vitro and inhibits tumor growth in vivo. Adv Healthc Mater. 2014;3(9):1486-95.

215. Feng Q, Liu Y, Huang J, Chen K, Huang J, Xiao K. Uptake, distribution, clearance, and toxicity of iron oxide nanoparticles with different sizes and coatings. Sci Rep. 2018;8(1):2082.

216. Lin J, Huang Z, Wu H, Zhou W, Jin P, Wei P, et al. Inhibition of autophagy enhances the anticancer activity of silver nanoparticles. Autophagy. 2014; 10(11):2006-20.

217. Chen J, Wang ZJ, Zhang KL, Xu YJ, Chen ZG, Hu XY. Selective Castrationresistant Prostate Cancer Photothermal Ablation With Copper Sulfide Nanoplates. Urology. 2019;125:248-55.

218. Dinda B, Dinda M, Kulsi G, Chakraborty A, Dinda S. Therapeutic potentials of plant iridoids in Alzheimer's and Parkinson's diseases: A review. Eur J Med Chem. 2019;169:185-99.

219. Cuervo AM, Stefanis L, Fredenburg R, Lansbury PT, Sulzer D. Impaired degradation of mutant alpha-synuclein by chaperone-mediated autophagy. Science. 2004;305(5688):1292-5.

220. Liu K, Shi N, Sun Y, Zhang T, Sun X. Therapeutic effects of rapamycin on MPTP-induced Parkinsonism in mice. Neurochem Res. 2013;38(1):201-7.

221. Richardson A, Galvan V, Lin AL, Oddo S. How longevity research can lead to therapies for Alzheimer's disease: The rapamycin story. Exp Gerontol. 2015; 68:51-8.

222. Kamalinia G, Khodagholi F, Atyabi F, Amini M, Shaerzadeh F, Sharifzadeh M, et al. Enhanced brain delivery of deferasirox-lactoferrin conjugates for iron chelation therapy in neurodegenerative disorders: in vitro and in vivo studies. Mol Pharm. 2013;10(12):4418-31.

223. Lee CM, Huang ST, Huang SH, Lin HW, Tsai HP, Wu JY, et al. C60 fullerenepentoxifylline dyad nanoparticles enhance autophagy to avoid cytotoxic effects caused by the $\beta$-amyloid peptide. Nanomedicine. 2011;7(1):107-14.

224. Bourdenx M, Daniel J, Genin E, Soria FN, Blanchard-Desce M, Bezard E, et al. Nanoparticles restore lysosomal acidification defects: Implications for
Parkinson and other lysosomal-related diseases. Autophagy. 2016;12(3):47283.

225. Zhang P, Yang L, He H, Deng Y. Differential variations of autophagy and apoptosis in permanent focal cerebral ischaemia rat model. Brain Inj. 2017; 31(8):1151-8.

226. Bosc D, Vezenkov L, Bortnik S, An J, Xu J, Choutka C, et al. A new quinolinebased chemical probe inhibits the autophagy-related cysteine protease ATG4B. Sci Rep. 2018;8(1):11653.

227. Plowey ED, Cherra SJ, Liu YJ, Chu CT. Role of autophagy in G2019S-LRRK2associated neurite shortening in differentiated SH-SY5Y cells. J Neurochem. 2008;105(3):1048-56.

228. Chakrabarti L, Eng J, Ivanov N, Garden GA, La Spada AR. Autophagy activation and enhanced mitophagy characterize the Purkinje cells of pcd mice prior to neuronal death. Mol Brain. 2009;2:24.

229. Bobryshev YV. Monocyte recruitment and foam cell formation in atherosclerosis. Micron. 2006;37(3):208-22.

230. Gao W, Sun Y, Cai M, Zhao Y, Cao W, Liu Z, et al. Copper sulfide nanoparticles as a photothermal switch for TRPV1 signaling to attenuate atherosclerosis. Nat Commun. 2018;9(1):231.

231. Xu Y, Wang $L$, Bai R, Zhang T, Chen C. Silver nanoparticles impede phorbol myristate acetate-induced monocyte-macrophage differentiation and autophagy. Nanoscale. 2015;7(38):16100-9.

232. Zhou HF, Yan H, Hu Y, Springer LE, Yang X, Wickline SA, et al. Fumagillin prodrug nanotherapy suppresses macrophage inflammatory response via endothelial nitric oxide. ACS Nano. 2014;8(7):7305-17.

233. Zhong $G$, Yang $X$, Jiang $X$, Kumar $A$, Long $H$, Xie J, et al. Dopamine-melanin nanoparticles scavenge reactive oxygen and nitrogen species and activate autophagy for osteoarthritis therapy. Nanoscale. 2019;11(24):11605-16.

\section{Publisher's Note}

Springer Nature remains neutral with regard to jurisdictional claims in published maps and institutional affiliations.

Ready to submit your research? Choose BMC and benefit from:

- fast, convenient online submission

- thorough peer review by experienced researchers in your field

- rapid publication on acceptance

- support for research data, including large and complex data types

- gold Open Access which fosters wider collaboration and increased citations

- maximum visibility for your research: over $100 \mathrm{M}$ website views per year

At $\mathrm{BMC}$, research is always in progress.

Learn more biomedcentral.com/submissions 